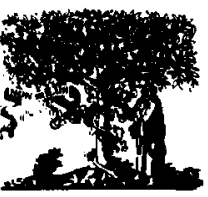

ELSEVIER
Advances in Colloid and Interface Science

69 (1996) 31-62
ADVANCES IN

COLLOID AND

INTERFACE

SCIENCE

\title{
A general model to describe the electrostatic potential at electrolyte oxide interfaces
}

\author{
R.E.G. van Hal*, J.C.T. Eijkel, P. Bergveld \\ MESA Research Institute, University of Twente, P.O. Box 217, 7500 AE Enschede, \\ The Netherlands
}

\begin{abstract}
Colloid chemists have proposed several theories to describe the charging mechanism of metal oxides in electrolyte solutions and the resulting electrical double layer at the oxide surface. In this paper a new general theory to describe the electrostatic potential at the metal oxide electrolyte solution interface is presented. This theory describes the variations of the electrostatic potential as a function of the differential double layer capacitance and the intrinsic buffer capacity. ISFET measurements are interpreted using this theory, and it is shown that these measurements can differentiate between the theories for the double layer and the theories for the charging mechanism for the oxide.
\end{abstract}

\section{Introduction}

In both colloid chemistry as well as chemical sensor technology there is a large interest in investigating the charging behaviour of metal oxides in electrolyte solutions. Colloid chemists use the surface charge and the zeta potential to investigate the interface between metal oxide and electrolyte solution. In chemical sensor technology the variation in

\footnotetext{
* Corresponding author.
} 
electrostatic potential to determine the $\mathrm{pH}$ of the electrolyte solution is the parameter of interest.

Especially the ISFET (ion sensitive field effect transistor) makes use of the $\mathrm{pH}$ dependent potential variations [1]. This $\mathrm{pH}$ sensitive electrode is made by techniques used in IC-technology and consists of a sensitive layer of metal oxide on top of a field effect transistor. This sensor is able to measure variations in the electrostatic potential but is not able to measure the absolute electrostatic potential.

Shortly after the introduction of the ISFET it was recognized that there is a direct relation between the $\mathrm{pH}$ sensitivity of the ISFET and the charging behaviour of metal (hydr)oxides [2]. For a long period, the site-dissociation model developed by Yates [3] was used to describe the ISFET $\mathrm{pH}$ sensitivity [4]. However, the derived expression was very complex and required some assumptions. In colloid chemistry, there is no consensus about the correct physical interpretation of the experimental observations on metal oxides. However, most models are, just as in the model for the ISFET pH sensitivity, a combination of a double layer model with a model that describes the adsorption of protons. This approach will be used to develop a new, more general model for the ISFET sensitivity. This new model can incorporate any combination of a double layer model and a charging mechanism described by surface reactions. Theoretical sensitivities are calculated using several combinations of double layer models and charging mechanisms. The theoretical calculations are verified with some experimental results.

\section{General expression for the $p H$ sensitivity of ISFETs}

Shortly after the introduction of the ISFET, it was noticed that these devices were sensitive to $\mathrm{pH}$ [2]. The operational mechanism of the ISFET is described by Bergveld and Sibbald [1] using an expression for the drain current, $\mathrm{I}_{\mathrm{D}}$, in the unsaturated region:

$I_{D}=\mu C_{o x} \frac{W}{L}\left(\left(V_{G S}-\left(E_{r e f}-\psi_{0}+\chi^{s o l}-\frac{\Phi_{S i}}{q}-\frac{Q_{0 x}+Q_{s s}}{C_{o x}}-\frac{Q_{B}}{C_{o x}}+2 \phi_{f}\right)\right) V_{D S}-1 / 2 V_{D S}^{2}\right)$

where $\mu$ is the average electron mobility in the channel; $W$ and $L$ are respectively the width and the length of the gate; $E_{\text {ref }}$ is the contribution of the reference electrode; $V_{D S}$ and $V_{G S}$ are respectively the drain source voltage and the gate source voltage; $\Phi_{\mathrm{Si}}$ is the silicon electron work function; $q$ is the elementary charge; $\mathrm{C}_{\mathrm{ox}}$ is the capacitance of the gate 
oxide; $Q_{o x}, Q_{s s}$ and $Q_{B}$ are the charges located in the oxide, charges located in surface states and interface states and the depletion charge respectively; $\chi^{\text {sol }}$ is the surface dipole potential of the solution, and $\phi_{\mathrm{f}}$ is the potential difference between the Fermi levels of doped and intrinsic silicon. All parameters are constant except the electrostatic potential, $\psi_{0}$ and the surface dipole potential, $\chi^{\text {sol }}$. The surface dipole potential is supposed to be independent of $\mathrm{pH}$ and changes in the drain current are therefore attributed to changes in the electrostatic potential, $\psi_{0}$, only.

From the short response times and the observed sensitivity below $59.2 \mathrm{mV} / \mathrm{pH}$, it was initially concluded that surface reactions between the gate insulator and the electrolyte solution should determine the primary response mechanism [5]. The surface reactions will build up a charge at the oxide surface. Due to this charge an electrostatic potential, $\Psi_{0}$, is developed in the electrolyte solution near the oxide surface (Fig. 1). This potential between electrolyte solution and insulator surface causes a proton concentration difference between bulk and surface that is according to Boltzmann:

$\mathrm{a}_{\mathrm{H}_{\mathrm{S}}^{+}}=\mathrm{a}_{\mathrm{H}_{\mathrm{B}}^{+}} \exp \frac{-\mathrm{q} \Psi_{0}}{\mathrm{kT}}$
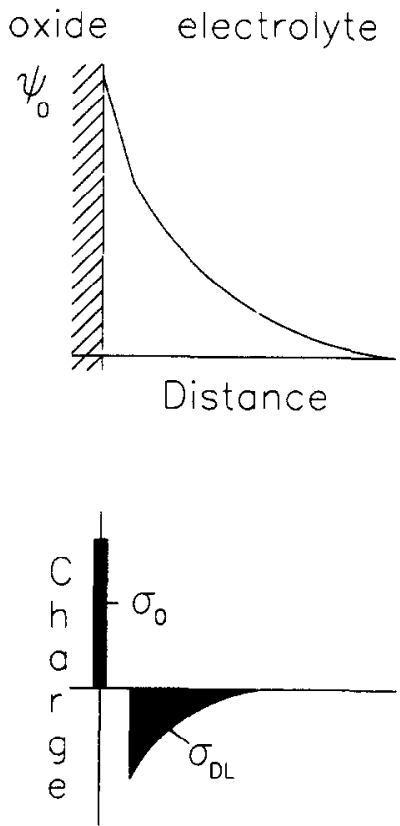

Fig. 1. Potential profile and charge distribution at an oxide electrolyte solution interface. 
or

$\mathrm{pH}_{\mathrm{S}}=\mathrm{pH}_{\mathrm{B}}+\frac{\mathrm{q} \Psi_{0}}{2.3 \mathrm{kT}}$

where $\mathrm{a}_{\mathrm{H}_{\mathrm{i}}^{+}}$is the activity of $\mathrm{H}^{+} ; \mathrm{q}$ is the elementary charge, $\mathrm{k}$ is the Boltzmann constant and $\mathrm{T}$ is the absolute temperature. The subscripts $B$ and $S$ refer to the bulk and the surface, respectively. The capability of the surface to store charge as result of a small change in the $\mathrm{H}^{+}$ concentration at the surface is directly related to the intrinsic buffer capacity, $\beta_{\text {int }}$ :

$\frac{\delta \sigma_{0}}{\delta p H_{S}}=-q \frac{\delta[B]}{\delta p H_{S}}=-q \beta_{\text {int }}$

where $\sigma_{0}$ is the surface charge per unit area and [B] is the number of charged groups, defined as the number of negatively charged groups minus the number of positively charged groups, per unit area. The buffer capacity, $\beta_{\text {int }}$, is called the intrinsic buffer capacity because it is the capability to buffer small changes in the surface $\mathrm{pH}\left(\mathrm{pH}_{\mathrm{s}}\right)$, but not in the bulk $\mathrm{pH}\left(\mathrm{pH}_{\mathrm{B}}\right)$.

Because of charge neutrality, an equal but opposite charge is built up in the electrolyte solution side of the double layer, $\sigma_{\mathrm{DL}}$ (Fig. 1). This charge can be described as a function of the integral double layer capacitance, $\mathrm{C}_{\mathrm{i}}$, often denoted as $\mathrm{K}$, and the electrostatic potential:

$\sigma_{\mathrm{DL}}=-\mathrm{C}_{\mathrm{i}} \psi_{0}=-\sigma_{0}$

The integral capacitance will be used later to calculate the total response of the ISFET on changes in $\mathrm{pH}$. The ability of the electrolyte solution to adjust the amount of stored charge as result of a small change in the electrostatic potential is the differential capacitance, $\mathrm{C}_{\mathrm{dif}}$ :

$\frac{\delta \sigma_{\mathrm{DL}}}{\delta \psi_{0}}=-\frac{\delta \sigma_{0}}{\delta \psi_{0}}=-\mathrm{C}_{\mathrm{dif}}$

Combination of (4) and (6) leads to an expression for the sensitivity of the electrostatic potential towards changes in $\mathrm{a}_{\mathrm{H}_{\mathrm{S}}^{+}}$:

$$
\frac{\delta \psi_{0}}{\delta \mathrm{pH}_{\mathrm{S}}}=\frac{\delta \psi_{0}}{\delta \sigma_{0}} \frac{\delta \sigma_{0}}{\delta \mathrm{pH} H_{\mathrm{S}}}=\frac{-\mathrm{q} \beta_{\text {int }}}{\mathrm{C}_{\text {dif }}}
$$


Combination of this expression with the analogue of the Nernst equation (Eq. (3)) yields:

$\frac{\delta \psi_{0}}{\delta\left(\mathrm{pH}_{\mathrm{B}}+\frac{q \psi_{0}}{2.3 \mathrm{kT}}\right)}=\frac{-q \beta_{\text {int }}}{\mathrm{C}_{\text {dif }}}$

Rearrangement of (8) gives a general expression for the sensitivity of the electrostatic potential to changes in the bulk $\mathrm{pH}$ :

$\frac{\delta \psi_{0}}{\delta p H_{B}}=-2.3 \frac{\mathrm{kT}}{\mathrm{q}} \alpha$

with

$$
\alpha=\frac{1}{\frac{2.3 \mathrm{kT} \mathrm{C} \mathrm{dif}_{\mathrm{f}}}{\mathrm{q}^{2} \beta_{\mathrm{int}}}+1}
$$

Note that $\alpha$ is a dimensionless sensitivity parameter. The value of $\alpha$ varies between 0 and 1 depending on the intrinsic buffer capacity and the differential capacitance. For a sensitivity close to the theoretical maximum, $\alpha$ approaches 1 , the intrinsic buffer capacity should be high and the differential capacitance should be small, as can be concluded from Eq. (10). A sensitivity close to zero can theoretically be derived when the intrinsic buffer capacity approaches zero. The key parameters, intrinsic buffer capacity and the differential capacitance are further investigated in the following paragraphs.

\section{The intrinsic buffer capacity}

\subsection{Introduction}

There are two general approaches in colloid chemistry to describe the titration data of oxides. The porous gel model was suggested by Lyklema as a possible explanation for the very high values of titratable charge on some oxides [6]. The idea is that $\mathrm{H}^{+}, \mathrm{OH}^{-}$and counter ions can penetrate into porous layers at the surface of the oxide. In this way quite large amounts of charge could be developed while there is still a reasonable separation between the charged groups. A complete analysis 
of this model is given by Perram et al. [7]. It should be noted, however, that there is no independent evidence for porous layers on most oxide surfaces, except for silica. Therefore, this model is not treated in this paper.

The second approach describes the charging mechanism of oxides by surface reactions. This approach is in agreement with the conclusions drawn by Siu and Cobbold from the fast response times of ISFETs [5]. There are several theories that describe the interactions as surface interactions. The principal features of all these theories are:

- Interactions take place at specific sites

- Interactions can be described via mass law equations

- Surface charge results from these interactions

- The effect of surface charge on the interactions can be taken into account by applying the double layer theory.

In this section the site-dissociation model introduced by Yates et al. [3] and the MUSIC model introduced by Hiemstra et al. [8] are used to derive the intrinsic buffer capacity for several oxides and silicon nitride. Other models like the one-pK model [9] can also be used to calculate the intrinsic buffer capacity but are not treated in this section. The one-pK model can be considered as a special case of the MUSIC model.

\subsection{The site-dissociation model}

The site-dissociation model is developed to describe the charging mechanism of the oxide side of the double layer [3]. This model can easily be expanded to describe the charging mechanism of silicon nitride.

\section{Oxides}

The site-dissociation model describes the charging of an oxide as the result of an equilibrium between the $\mathrm{AOH}$ surface sites and the $\mathrm{H}^{+}$ions in the bulk of the solution [3]. The surface reactions are:

$\mathrm{AOH} \rightleftarrows \mathrm{AO}^{-}+\mathrm{H}_{\mathrm{S}}^{+}$

and

$$
\mathrm{AOH}_{2}^{+} \rightleftarrows \mathrm{AOH}+\mathrm{H}_{\mathrm{S}}^{+}
$$

with the following thermodynamic equations:

$$
\mu_{\mathrm{AOH}}^{0}+\mathrm{kT}^{\prime} \ln v_{\mathrm{AOH}}=\mu_{\mathrm{AO}}^{0}+\mathrm{kT} \ln v_{\mathrm{AO}^{-}}+\mu_{\mathrm{H}_{\mathrm{S}}^{+}}^{0}+\mathrm{kT} \ln \mathrm{a}_{\mathrm{H}_{\mathrm{S}}^{+}}
$$


and

$\mu_{\mathrm{AOH}}^{0}+\mathrm{kT} \ln v_{\mathrm{AOH}_{2}^{+}}=\mu_{\mathrm{AOH}}^{0}+\mathrm{kT} \ln v_{\mathrm{AOH}}+\mu_{\mathrm{H}_{\mathrm{S}}^{+}}^{0}+\mathrm{kT} \ln \mathrm{a}_{\mathrm{H}_{\mathrm{S}}^{+}}$

where $v_{i}$ is the surface activity and $\mu_{\mathrm{i}}^{0}$ is the standard chemical potential of species $i$.

Equations (13) and (14) can be simplified to:

$\frac{v_{\mathrm{AO}^{-}} \mathrm{a}_{\mathrm{H}_{\mathrm{S}}^{+}}}{v_{\mathrm{AOH}}}=\mathrm{K}_{\mathrm{a}}$ with $\quad \mathrm{K}_{\mathrm{a}}=\exp \frac{\mu_{\mathrm{AOH}}^{0}-\mu_{\mathrm{AO}^{-}}^{0}-\mu_{\mathrm{H}_{\mathrm{B}}^{+}}^{0}}{\mathrm{kT}}$

and

$\frac{v_{\mathrm{AOH}}}{v_{\mathrm{AOH}_{2}^{+}}} \frac{\mathrm{a}_{\mathrm{H}_{\mathrm{S}}^{+}}}{\mathrm{N}_{\mathrm{b}}}=\mathrm{K}_{\mathrm{b}}$ with $\quad \mathrm{K}_{\mathrm{b}}=\exp \frac{\mu_{\mathrm{AOH}}^{0}-\mu_{\mathrm{AOH}}^{0}-\mu_{\mathrm{H}_{\mathrm{B}}^{+}}^{0}}{\mathrm{kT}}$

where the $K$ values are dimensionless intrinsic dissociation constants. It is clear that the $K$ values are real constants independent of the ionization state of the oxide surface. The relation between the surface activity and the bulk activity of $\mathrm{H}^{+}$is given by the Boltzmann equation (2). The surface charge density, $\sigma_{0}$, is given by:

$\sigma_{0}=\mathrm{q}\left(v_{\mathrm{AOH}_{2}^{+}}-v_{\mathrm{AO}^{-}}\right)=\mathrm{qN}_{\mathrm{s}}\left(\Theta^{+}-\Theta^{-}\right)$

where $N_{s}$ is the density of the available sites; $\Theta^{+}$and $\Theta^{-}$are the fractions $\mathrm{AOH}_{2}^{+}$and $\mathrm{AO}^{-}$of $\mathrm{N}_{\mathrm{s}}$, respectively. The fractions $\Theta^{+}$and $\Theta^{-}$are calculated from Eqs. (13) and (14), and substituted in (17) to give:

$\sigma_{0}=q N_{s}\left(\frac{a_{H_{S}^{+}}^{2}-K_{a} K_{b}}{K_{a} K_{b}+K_{b} a_{H_{s}^{+}}+a_{H_{s}^{+}}^{2}}\right)=-q[B]$

Equation (18) can be differentiated to $\mathrm{pH}$, to find the intrinsic buffer capacity as defined by Eq. (4):

$\frac{\delta \sigma_{0}}{\delta p H_{S}}=-q \frac{\delta[B]}{\delta p H_{S}}=-q \beta_{\text {int }}$ 
where $\beta_{\text {int }}$ is the intrinsic buffer capacity with the dimension of groups per unit area.

Substitution of Eq. (18) in (19) and elaboration gives the following expression for the intrinsic buffer capacity:

$\beta_{\text {int }}=N_{\mathrm{s}} \frac{\mathrm{K}_{\mathrm{b}} \mathrm{a}_{\mathrm{H}_{\mathrm{S}}^{+}}^{2}+4 \mathrm{~K}_{\mathrm{a}} \mathrm{K}_{\mathrm{b}} \mathrm{a}_{\mathrm{H}_{\mathrm{S}}^{+}}+\mathrm{K}_{\mathrm{a}} \mathrm{K}_{\mathrm{b}}^{2}}{\left(\mathrm{~K}_{\mathrm{a}} \mathrm{K}_{\mathrm{b}}+\mathrm{K}_{\mathrm{b}} \mathrm{a}_{\mathrm{H}_{\mathrm{S}}^{+}}+\mathrm{a}_{\mathrm{H}_{\mathrm{S}}^{+}}^{2}\right)^{2}} 2.3 \mathrm{a}_{\mathrm{H}_{\mathrm{S}}^{+}}$

This expression is valid for all oxides whose charging mechanism can be described by the association and dissociation of one amphoteric group. The values of $\mathrm{N}_{\mathrm{s}}, \mathrm{K}_{\mathrm{a}}$ and $\mathrm{K}_{\mathrm{b}}$ are oxide dependent. Another important parameter to characterize the oxide is the $\mathrm{pH}$ at the point of zero charge, $\mathrm{pH}_{\mathrm{pzc}}$. At the $\mathrm{pH}_{\mathrm{pzc}}$, the number of positively and negatively charged groups on the surface is equal and consequently there will be no net charge on the surface. Table 1 shows the literature values of several oxide constants.

Table 1

Literature values of several constants

\begin{tabular}{lrrrll}
\hline & $\mathrm{pK}_{\mathrm{a}}$ & $\mathrm{pK}_{\mathrm{b}}$ & \multicolumn{1}{c}{$\mathrm{N}_{\mathrm{s}}$} & $\mathrm{pH}_{\mathrm{wzc}}$ & Ref. \\
\hline $\mathrm{SiO}_{2}$ & 6 & -2 & $5.10^{18}$ & 2 & {$[10]$} \\
$\mathrm{Al}_{2} \mathrm{O}_{3}$ & 10 & 6 & $8.10^{18}$ & 8 & {$[10]$} \\
$\mathrm{Ta}_{2} \mathrm{O}_{5}$ & 4 & 2 & $10.10^{18}$ & 3 & {$[11]$} \\
\hline
\end{tabular}

From Eq. (20), it can be seen that the number of surface sites influences the intrinsic buffer capacity. Hydrolysis of the surface will create more surface sites and thus a rise in the intrinsic buffer capacity and the sensitivity.

\subsection{The MUSIC model}

Hiemstra et al. introduced a multisite complexation model (MUSIC) to describe the charging mechanism of oxides [8]. This relatively new model is based on crystallographic considerations and can unify the site-dissociation model [3] and the one-pK model [9]. In contrast to the site-dissociation model where the intrinsic dissociation constants are 
derived by fitting titration data, the MUSIC model is able to estimate the value of the intrinsic dissociation constants of the active surface groups from physical parameters. The intrinsic dissociation constants depend on many factors, e.g, the valence of the metal ion, the number of cations coordinating with a ligand and the number of ligands surrounding the metal ion. These factors are specific for any particular oxide having different reactive groups are present on different oxides. It is therefore impossible to derive a description which is generally valid for all types of oxide. Every oxide should be treated separately.

\section{Silicon dioxide}

According to the MUSIC model, the surface of silicon dioxide consists of two types of groups, silanol groups and siloxane groups [12]. The dissociation reactions of these groups are:

$$
\begin{aligned}
& \mathrm{SiOH} \rightleftarrows \mathrm{SiO}^{-}+\mathrm{H}_{\mathrm{S}}^{+} \quad \text { with dissociation constant: } \mathrm{K}_{\mathrm{a}} \\
& \mathrm{SiOH}_{2}^{+} \rightleftarrows \mathrm{SiOH}+\mathrm{H}_{\mathrm{S}}^{+} \quad \text { with dissociation constant: } \mathrm{K}_{\mathrm{b}}
\end{aligned}
$$

and

$$
\mathrm{Si}_{2} \mathrm{OH}^{+} \rightleftarrows \mathrm{Si}_{2} \mathrm{O}+\mathrm{H}_{\mathrm{S}}^{+} \quad \text { with dissociation constant: } \mathrm{K}_{\mathrm{d}}
$$

The estimated value for the intrinsic dissociation constant of the doubly coordinated $\mathrm{Si}_{2} \mathrm{O}$ is extremely high $\left(\mathrm{pK}_{\mathrm{d}}=-16.9\right)$ which means that these groups can be considered as inert in water. The value of $\mathrm{pK}_{\mathrm{b}}(-1.9)$ indicates that protonation of the silanol groups is negligible in the normal $\mathrm{pH}$ range. Notice that this value for $\mathrm{pK}_{\mathrm{b}}$ is very close to the value used in the site-dissociation model for the same reaction. The charging of silicon dioxide is thus fully dominated by the dissociation of singly coordinated neutral groups $\left(\mathrm{pK}_{\mathrm{a}}=7.5\right.$ ) described in Eq. (21). Analogous to the previous derivation for the surface charge in the site-dissociation model, the surface charge is:

$\sigma_{0}=\mathrm{qN}_{\mathrm{s}} \frac{-\mathrm{K}_{\mathrm{a}}}{\mathrm{K}_{\mathrm{a}}+\mathrm{a}_{\mathrm{H}_{\mathrm{s}}^{+}}}$

where $\mathrm{N}_{\mathrm{s}}$ is the number of singly coordinated sites. The intrinsic buffer capacity is derived from (24) as: 
$\beta_{\text {int }}=N_{\mathrm{s}} \frac{\mathrm{K}_{\mathrm{a}}}{\left(\mathrm{K}_{\mathrm{a}}+\mathrm{a}_{\mathrm{H}_{\mathrm{S}}^{+}}\right)^{2}} 2.3 \mathrm{a}_{\mathrm{H}_{\mathrm{S}}^{+}}$

This expression is valid for all surfaces that contain one type of acidic surface groups. Notice that Eq. (25) is equal to Eq. (20) assuming that protonation of the hydroxy groups is negligible as was done in this case.

\section{Aluminum oxide}

The aluminum oxide structure is characterized by aluminum ions in hexa-coordination with six ligands [13]. The aluminum ions distribute their charge over the six surrounding ligands, neutralizing on the average half a unit of charge per $\mathrm{AlOH}$ bond. Therefore there are two aluminum ions needed to neutralize the negative charge of one $\mathrm{OH}^{-}$. The proton dissociation reaction for singly coordinated oxygens can be formulated as:

$\mathrm{AlOH}_{2}^{1 / 2} \rightleftarrows \mathrm{AlOH}^{-1 / 2}+\mathrm{H}_{\mathrm{S}}^{+} \quad$ with dissociation constant: $\mathrm{K}_{\mathrm{e}}$

and for doubly coordinated oxygens as:

$\mathrm{Al}_{2} \mathrm{OH} \rightleftarrows \mathrm{Al}_{2} \mathrm{O}^{-}+\mathrm{H}_{\mathrm{S}}^{+} \quad$ with dissociation constant: $\mathrm{K}_{\mathrm{f}}$

and

$\mathrm{Al}_{2} \mathrm{OH}_{2}^{+} \rightleftarrows \mathrm{Al}_{2} \mathrm{OH}+\mathrm{H}_{\mathrm{S}}^{+} \quad$ with dissociation constant: $\mathrm{K}_{\mathrm{g}}$

In the normal $\mathrm{pH}$ range, both reactions of the doubly coordinated oxygens are negligible with respect to the charge generation at the surface $\left(\mathrm{pK}_{\mathrm{f}}=12.3, \mathrm{pK}_{\mathrm{g}}=-1.5\right)$. Analogous to the previous calculations, the surface charge is calculated from Eq. (26) to be:

$\sigma_{0}=0.5 \mathrm{qN}_{\mathrm{s}}\left(\frac{\mathrm{a}_{\mathrm{H}_{\mathrm{S}}^{+}}}{\mathrm{K}_{\mathrm{e}}+\mathrm{a}_{\mathrm{H}_{\mathrm{S}}^{+}}}-\frac{\mathrm{K}_{\mathrm{e}}}{\mathrm{K}_{\mathrm{e}}+\mathrm{a}_{\mathrm{H}_{\mathrm{S}}^{+}}}\right)$

where $\mathrm{N}_{\mathrm{s}}$ is the number of singly coordinated sites. The intrinsic buffer capacity is derived from (29) to be:

$\beta_{\text {int }}=\mathrm{N}_{\mathrm{s}} \frac{\mathrm{K}_{\mathrm{e}}}{\left(\mathrm{K}_{\mathrm{e}}+\mathrm{a}_{\mathrm{H}_{\mathrm{S}}^{+}}\right)^{2}} 2.3 \mathrm{a}_{\mathrm{H}_{\mathrm{S}}^{+}}$ 
The doubly coordinated oxygens are neutral in the normal $\mathrm{pH}$ range. The point of zero charge of $\mathrm{Al}_{2} \mathrm{O}_{3}$ is therefore determined by the reaction of single coordinated oxygens and is equal to $\mathrm{pK}_{e}(8.5)$. The expressions for the surface charge and the intrinsic buffer capacity are valid for all surfaces that can be described by one type of group having half a unit of charge.

\section{The differential capacitance}

\subsection{Introduction}

There are several models to describe the double layer capacitance. Westall and Hohl have compared five of these models for the oxide electrolyte solution interface [14]. They showed that it is possible to describe the titration data of oxides with all of these models, taking the appropriate choice of parameters. However, from the titration curves of colloid suspensions of several oxides, it is known that the background electrolyte has a large influence on the surface charge [15]. This dependence is ascribed to variations in the double layer capacitance. Van Kerkhof showed that in dynamic experiments ISFETs are also sensitive to the electrolyte concentration in the solution [16]. Therefore, it was concluded that the Helmholtz model is not a suitable model for a description of the double layer capacitance in the derivation of the sensitivity of ISFETs and the titration curves of oxides. The GouyChapman-Stern model, which is most widely used to describe the double layer structure in colloid science and in ISFET literature, as well as the more simple Gouy-Chapman model, which is sometimes used in colloid science [17], describe the double layer as a function of the ionic strength. Therefore, both models are considered in the next sections.

\subsection{The Gouy-Chapman theory}

Already in the beginning of this century Gouy and Chapman proposed independently the idea of a diffuse layer to interpret the capacitive behaviour of an electrode/electrolyte solution interface. The excess charge in the solution side of the interface is equal in value to that on the solid state surface, but is of opposite sign. The ions in the solution are therefore electrostatically attracted to the solid state surface but the attraction is counteracted by the random thermal motion which acts to 
equalize the concentration throughout the solution. The equilibrium between these opposite trends is given by the well-known Boltzmann equation:

$c_{i}(x)=c_{i}^{0} \exp \left(\frac{-z_{i} q \phi_{x}}{k T}\right)$

where $\phi_{\mathrm{x}}$ is the potential at any distance $\mathrm{x}$ with respect to the bulk of the solution; $c_{i}(x)$ and $c_{i}^{0}$ are the molar concentrations of species $i$ at a distance $\mathrm{x}$ and in the bulk of the solution respectively and $z_{i}$ is the magnitude of the charge on the ions. Combination of the Boltzmann equation with the Poisson equation, that relates the charge density with the potential, gives an expression for the surface charge density [18]:

$\sigma_{\mathrm{DL}}=-\left(8 \mathrm{kT} \varepsilon_{0} \mathrm{n}^{0}\right)^{1 / 2} \sinh \left(\frac{\mathrm{zq} \psi_{0}}{2 \mathrm{kT}}\right)=-\mathrm{C}_{\mathrm{i}} \psi_{0}=-\sigma_{0}$

where $\varepsilon_{0}$ is the permittivity of free space and $\varepsilon$ is the relative permittivity; $\mathrm{n}^{0}$ is the number concentration of each ion in the bulk. The parameters $\mathrm{C}_{\mathrm{i}}, \Psi_{0}$ and $\sigma_{0}$ have been defined in Section 2. Differentiation of Eq. (32) with respect to $\Psi_{0}$ and rearrangement gives the following expression for the differential capacitance:

$\mathrm{C}_{\mathrm{dif}}=\left(\frac{2 \mathrm{z}^{2} \mathrm{q}^{2} \varepsilon \varepsilon_{0} \mathrm{n}^{0}}{\mathrm{kT}}\right)^{1 / 2} \cosh \left(\frac{\mathrm{zq} \Psi_{0}}{2 \mathrm{kT}}\right)$

The Gouy-Chapman theory has one major drawback. The ions are considered as point charges that can approach the surface arbitrarily close. This assumption causes unrealistic high concentrations of ions near the surface at high values of $\Psi_{0}$. An adjustment to solve this problem was first suggested by Stern [19] and is described in the next section.

\subsection{The Gouy-Chapman-Stern theory}

The Gouy-Chapman-Stern model involves a diffuse layer of charge in the solution starting at a distance $\mathrm{x}_{2}$ from the surface. This distance $\mathrm{x}_{2}$ is the plane of closest approach for the centres of the ions in the solution. The charge in the diffuse layer is [18]: 
$\sigma_{\mathrm{DL}}=-\left(8 \mathrm{kT} \varepsilon \varepsilon_{0} \mathrm{n}^{0}\right)^{1 / 2} \sinh \left(\frac{\mathrm{zq} \phi_{2}}{2 \mathrm{kT}}\right)=-\mathrm{C}_{\mathrm{i}} \psi_{0}=-\sigma_{0}$

where $\phi_{2}$ is the potential at $x_{2}$. Differentiating and rearranging (34) gives the following expression for the differential capacitance:

$\mathrm{C}_{\mathrm{dif}}=\frac{\left(\frac{2 \varepsilon \varepsilon_{0} \mathrm{z}^{2} \mathrm{q}^{2} \mathrm{n}^{0}}{\mathrm{kT}}\right)^{1 / 2} \cosh \left(\frac{\mathrm{zq} \phi_{2}}{2 \mathrm{kT}}\right)}{1+\left(\frac{\mathrm{x}_{2}}{\varepsilon \varepsilon_{0}}\right)\left(\frac{2 \varepsilon \varepsilon_{0} \mathrm{z}^{2} \mathrm{q}^{2} \mathrm{n}^{0}}{\mathrm{kT}}\right)^{1 / 2} \cosh \left(\frac{\mathrm{zq} \phi_{2}}{2 \mathrm{kT}}\right)}$

or more simply:

$\frac{1}{C_{\text {dif }}}=\frac{x_{2}}{\varepsilon \varepsilon_{0}}+\frac{1}{\left(\frac{2 \varepsilon \varepsilon_{0} z^{2} q^{2} n^{0}}{k T}\right)^{1 / 2} \cosh \left(\frac{z q \phi_{2}}{2 k T}\right)}$

This expression shows that the differential capacitance is made up of two components. The former part of this expression describes the contribution of the Stern layer, whereas the latter part describes the diffuse layer contribution. The integral capacitance can also be described as two capacitors in series [18]. Using this description for the integral capacitance, the relation between $\psi_{0}$ and $\phi_{2}$ can be expressed by:

$\psi_{0}=\frac{\sigma_{0}}{C_{i, d}}+\frac{\sigma_{0}}{C_{i, s t}}=\phi_{2}+\frac{\left(8 \mathrm{kT} \varepsilon \varepsilon_{0} \mathrm{n}^{0}\right)^{1 / 2} \sinh \left(\frac{\mathrm{zq} \phi_{2}}{2 \mathrm{kT}}\right)}{\mathrm{C}_{\mathrm{i}, \mathrm{st}}}$

where $C_{i, d}$ and $C_{i, s t}$ are the integral capacitance of the diffuse layer and the Stern layer, respectively.

\section{Theoretical sensitivities}

\subsection{Introduction}

In Section 2 , it was shown that the sensitivity of the electrostatic potential to changes in $\mathrm{pH}_{\mathrm{B}}$ is related to the intrinsic buffer capacity and the differential capacitance. In Section 3 several models were introduced to describe the oxide charging mechanism and to obtain an 
expression for the intrinsic buffer capacity. In Section 4, two double layer models are elaborated to describe the charge distribution and to calculate the differential capacitance. In this section, the theoretical sensitivity is calculated using several combinations of the models described above.

\subsection{Site-dissociation and Gouy-Chapman model}

Dzombak and Morel used the site-dissociation model in combination with the Gouy-Chapman model to describe the surface complexation of hydrous ferric oxide [17]. An important parameter in their description is the shear plane which is used in electrophoresis theory. This is an imaginary plane which is considered to lie close to the solid surface and within which the fluid is stationary. In the case of a particle undergoing electrophoresis, the plane of shear forms a sheath which envelopes the particle. The analysis of the forces on the solid or the liquid can be carried out in terms of the zeta potential which is the average potential at the surface of shear. With the choice of a suitable distance for the shear plane, the measured zeta potentials and titration data can be fit. However, until now this model was not verified with the electrostatic potential, $\psi_{0}$, measured by ISFETs.

To calculate the electrostatic potential, the shear plane is of no importance and therefore one fitting parameter can be skipped. The relation between the parameters $\mathrm{a}_{\mathrm{H}_{\mathrm{S}}^{+}}$and $\psi_{0}$ can be derived by solving (5) and (18) to obtain:

$a_{\mathrm{H}_{\mathrm{S}}^{+}}=\frac{\mathrm{K}_{\mathrm{b}} \mathrm{C}_{\mathrm{i}} \psi_{0}+\sqrt{\left(\mathrm{K}_{\mathrm{b}} \mathrm{C}_{\mathrm{i}} \psi_{0}\right)^{2}+4 \mathrm{~K}_{\mathrm{a}} \mathrm{K}_{\mathrm{b}}\left(\mathrm{q}^{2} \mathrm{~N}_{\mathrm{s}}^{2}-\mathrm{C}_{\mathrm{i}}^{2} \psi_{0}^{2}\right)}}{2\left(\mathrm{qN} \mathrm{N}_{\mathrm{s}}-\mathrm{C}_{\mathrm{i}} \psi_{0}\right)}$

This relation is necessary to link the calculated intrinsic buffer capacity and the differential capacitance.

Silicon dioxide

Figures 2 and 3 show respectively the theoretical electrostatic potential and the sensitivity parameter of silicon dioxide as function of $\mathrm{pH}_{\mathrm{B}}$ at three different electrolyte concentrations. The maximum sensitivity of the electrostatic potential lies between $\mathrm{pH} 6$ and 8 for $0.1 \mathrm{M}$, and between 5 and 9 for $1 \mathrm{mM}$. The low sensitivity around the point of zero charge $(\mathrm{pH}=2)$ is due to the low intrinsic buffer capacity as can be seen from Fig. 4. The large rise in the differential capacitance (Fig. 5) in 


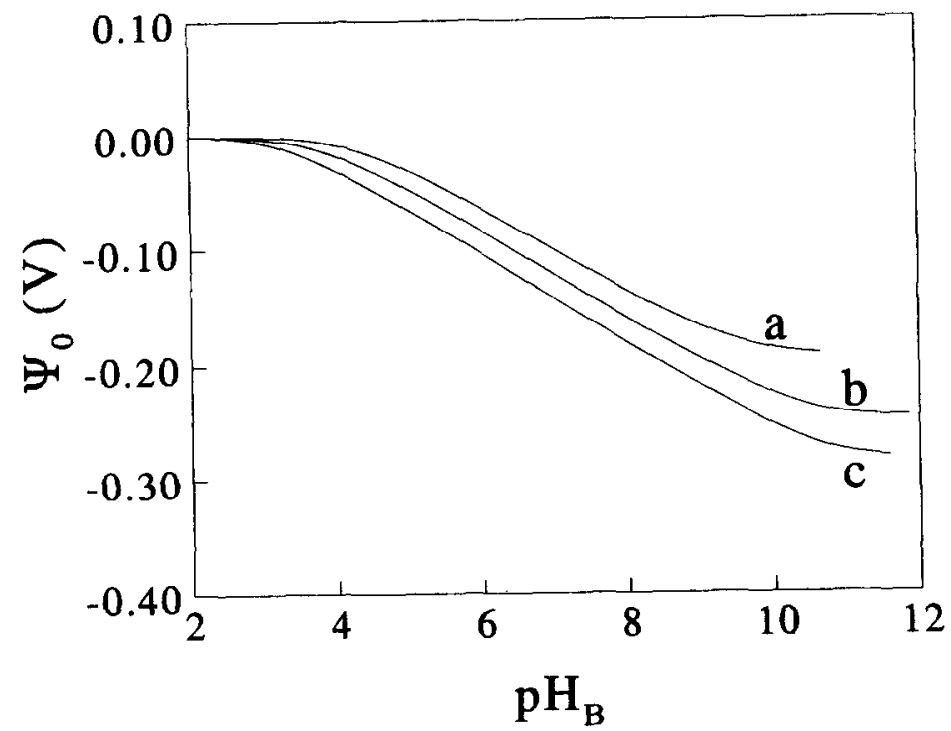

Fig. 2. The theoretical sensitivity of a $\mathrm{SiO}_{2}$ ISFET using the site-dissociation model and the Gouy-Chapman model (Eq. (3.47)): (a) $0.1 \mathrm{M}$, (b) $0.01 \mathrm{M}$, (c) $1 \mathrm{mM}$.

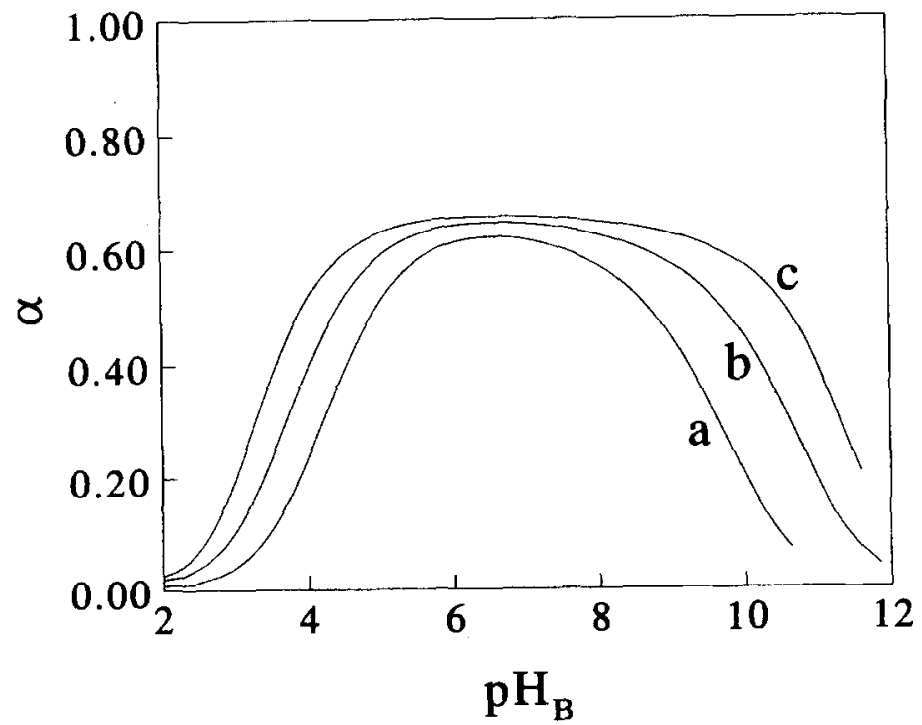

Fig. 3. The sensitivity parameter of a $\mathrm{SiO}_{2}$ ISFET using the site-dissociation model and the Gouy $\sim$ Chapman model (Eq. (3.10)): (a) $0.1 \mathrm{M}$, (b) $0.01 \mathrm{M}$, (c) $1 \mathrm{mM}$. 


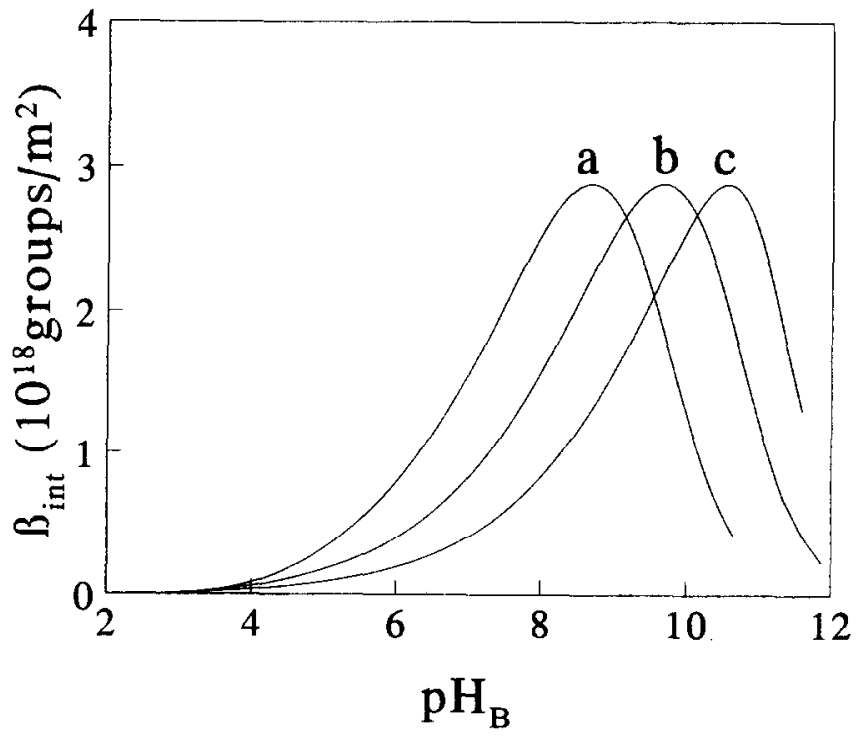

Fig. 4. The intrinsic buffer capacity of a $\mathrm{SiO}_{2}$ ISFET using the site-dissociation model and the Gouy-Chapman model (Eq. (3.24)): (a) $0.1 \mathrm{M}$, (b) $0.01 \mathrm{M}$, (c) $1 \mathrm{mM}$.

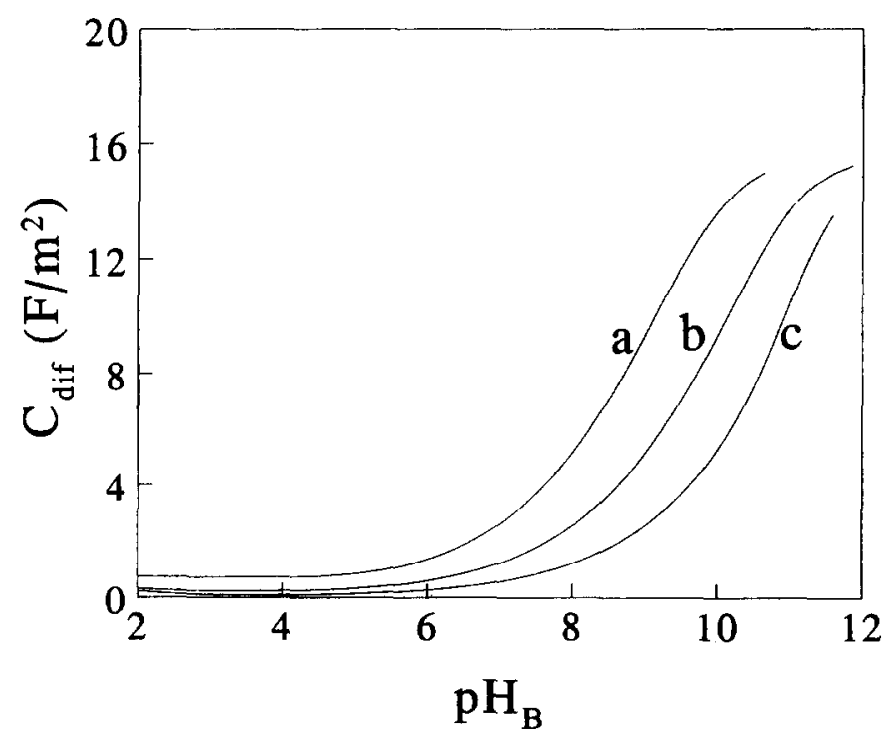

Fig. 5. The differential capacitance of a $\mathrm{SiO}_{2}$ ISFET using the site-dissociation model and the Gouy-Chapman model (Eq. (3.42)): (a) $0.1 \mathrm{M}$, (b) $0.01 \mathrm{M}$, (c) $1 \mathrm{mM}$. 
combination with the reduction of the intrinsic buffer capacity causes the decrease in sensitivity in basic solutions. The surface is already fully titrated around $\mathrm{pH} 10$ as can be concluded from the drop in the intrinsic buffer capacity (Fig. 4). Notice that there is a large dependency of the electrostatic potential on the electrolyte concentration.

\section{Aluminum oxide}

Figure 6 shows the theoretical electrostatic potential of aluminum oxide as function of $\mathrm{pH}_{\mathrm{B}}$ at three different electrolyte concentrations. Figure 7 shows, that, in contrast to silicon dioxide, the maximum sensitivity is reached around the point of zero charge $(\mathrm{pH}=8)$. This is due to the relatively high intrinsic buffer capacity of aluminum oxide (Fig. 8) compared to silicon dioxide (Fig. 4). The reduced sensitivity far from the point of zero charge is caused by the drop in the intrinsic buffer capacity and the rise in the differential capacitance (Fig. 9). The surface starts to become saturated what proceeds more slowly at lower electrolyte concentrations. Therefore, there is, just like in the case of silicon dioxide, a large dependency of the electrostatic potential on the electrolyte concentration.

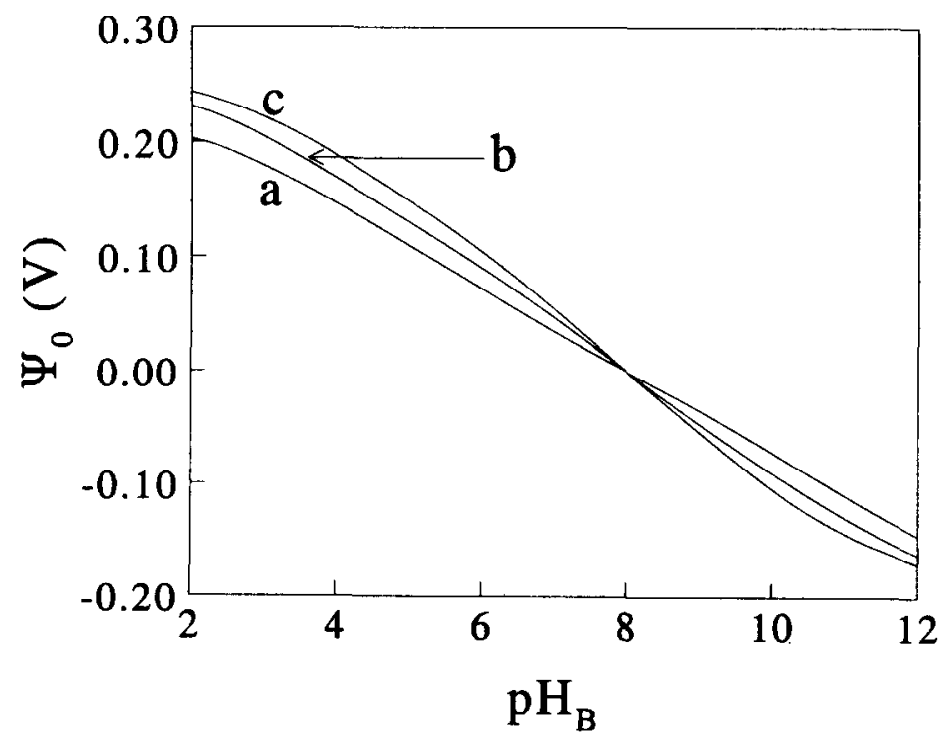

Fig. 6. The theoretical total response of $\mathrm{Al}_{2} \mathrm{O}_{3}$ ISFET using the site-dissociation model and the Gouy-Chapman model (Eq. (3.47)): (a) $0.1 \mathrm{M}$, (b) $0.01 \mathrm{M}$, (c) $1 \mathrm{mM}$. 


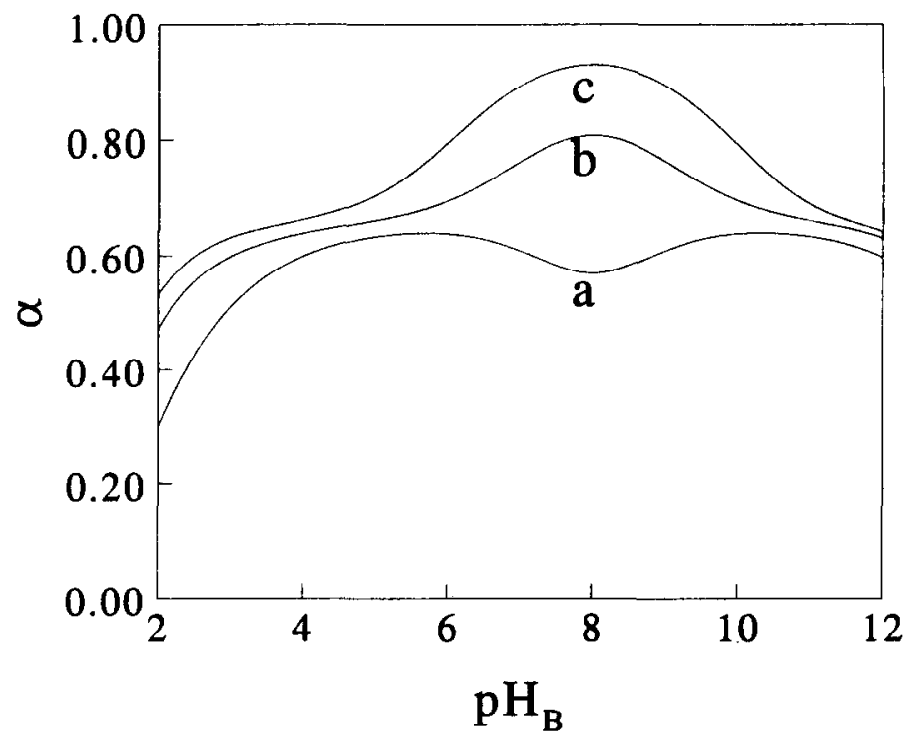

Fig. 7. The sensitivity parameter of a $\mathrm{Al}_{2} \mathrm{O}_{3}$ ISFET using the site-dissociation model and the Gouy-Chapman model (Eq. (3.10)): (a) $0.1 \mathrm{M}$, (b) $0.01 \mathrm{M}$, (c) $1 \mathrm{mM}$.

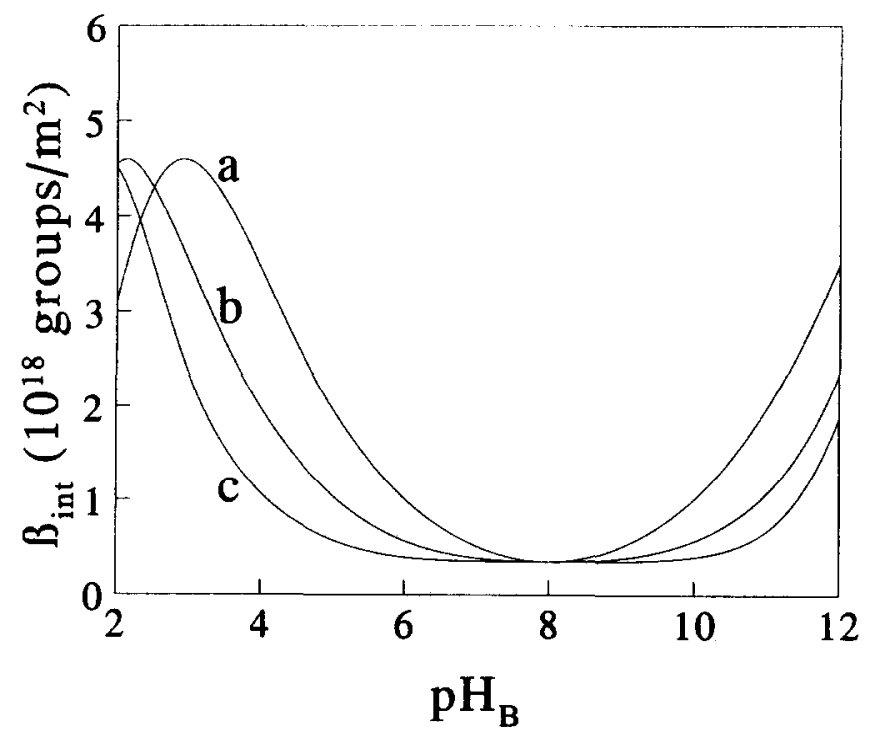

Fig. 8. The intrinsic buffer capacity of a $\mathrm{Al}_{2} \mathrm{O}_{3}$ ISFET using the site-dissociation model and the Gouy-Chapman model (Eq. (3.24)): (a) $0.1 \mathrm{M}$, (b) $0.01 \mathrm{M}$, (c) $1 \mathrm{mM}$. 


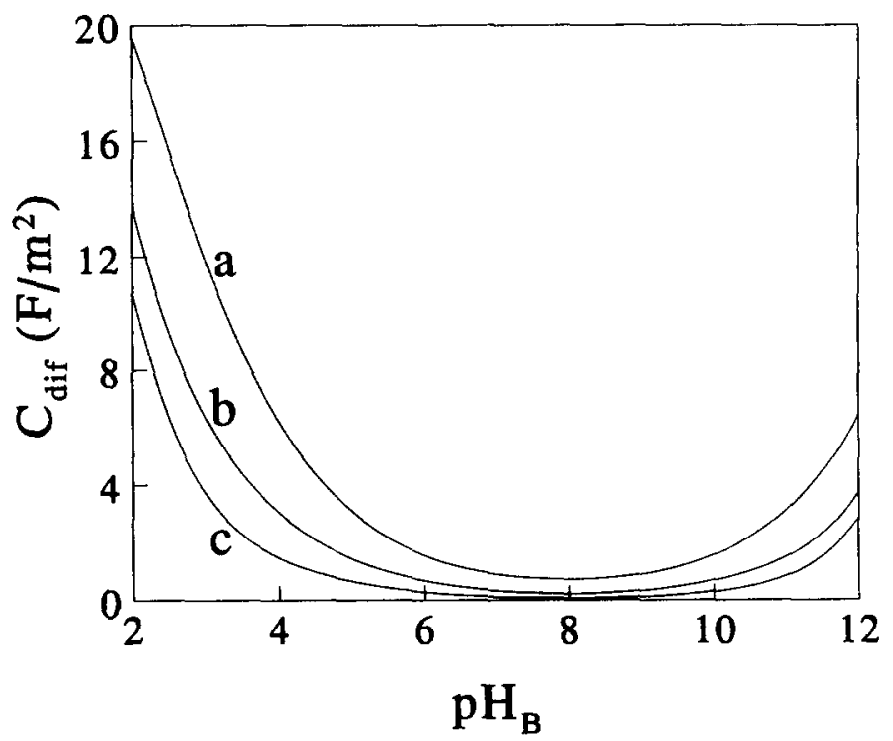

Fig. 9. The differential capacitance of a $\mathrm{Al}_{2} \mathrm{O}_{3}$ ISFET using the site-dissociation model and the Gouy-Chapman model (Eq. (3.42)): (a) $0.1 \mathrm{M}$, (b) $0.01 \mathrm{M}$, (c) $1 \mathrm{mM}$.

\subsection{Site-dissociation and Gouy-Chapman-Stern model}

The combination of the site-dissociation model with the Gouy-Chapman-Stern model is probably the most widely used combination to describe the oxide/electrolyte solution interface. A Stern capacitance of $0.2 \mathrm{~F} / \mathrm{m}^{2}$ is mostly used to describe the ISFET response. However, to describe the titration data of colloid suspensions values of 0.8 to $1.4 \mathrm{~F} / \mathrm{m}^{2}$ are taken. Recently, Hiemstra and Van Riemsdijk argued that the capacitance of the Stern layer on a non-porous well-ordered planar surface should be between 0.8 and $1.6 \mathrm{~F} / \mathrm{m}^{2}$ [20]. Therefore, a Stern layer capacitance of $0.2 \mathrm{~F} / \mathrm{m}^{2}$ and $0.8 \mathrm{~F} / \mathrm{m}^{2}$ will be used in this section to calculate the ISFET sensitivity. The surface activity of $\mathrm{H}^{+}$and the electrostatic potential are related by Eq. (38).

\section{Silicon dioxide}

Figure 10 shows the theoretical response of a SiO2 ISFET using a Stern capacitance of $0.8 \mathrm{~F} / \mathrm{m}^{2}$. The minimum sensitivity of these ISFETs lies around the point of zero charge as can be seen from the 


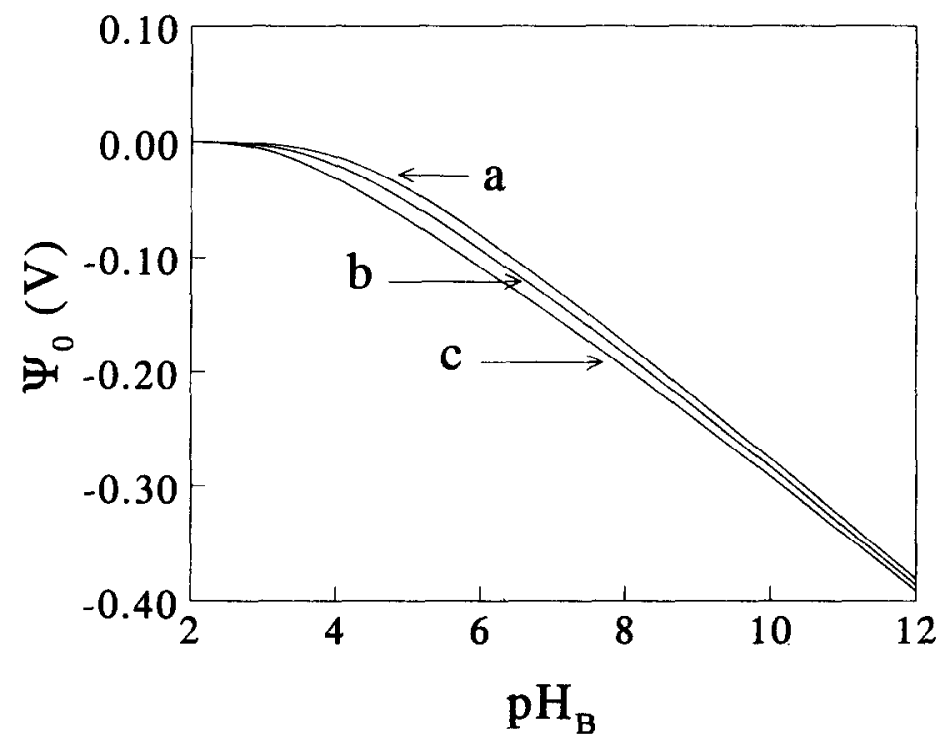

Fig. 10. The theoretical total response of a $\mathrm{SiO}_{2}$ ISFET using the site-dissociation model and the Gouy-Chapman-Stern model with $\mathrm{C}_{\mathrm{i}, \mathrm{st}}=0.80 \mathrm{~F} / \mathrm{m}^{2}$ (Eq. (3.47)): (a) $0.1 \mathrm{M}$, (b) $0.01 \mathrm{M}$, (c) $1 \mathrm{mM}$.

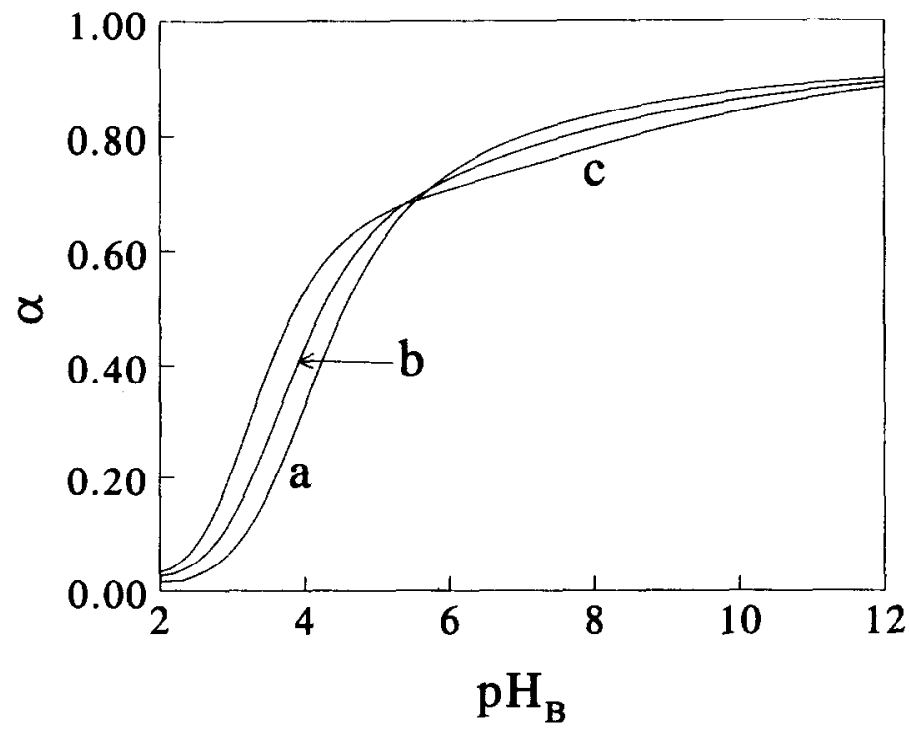

Fig. 11. The sensitivity parameter of a $\mathrm{SiO}_{2}$ ISFET using the site-dissociation model and the Gouy-Chapman-Stern model with $\mathrm{C}_{\mathrm{i}, \mathrm{st}}=0.80 \mathrm{~F} / \mathrm{m}^{2}$ (Eq. (3.10)): (a) $0.1 \mathrm{M}$, (b) 0.01 $\mathrm{M}$, (c) $1 \mathrm{mM}$. 


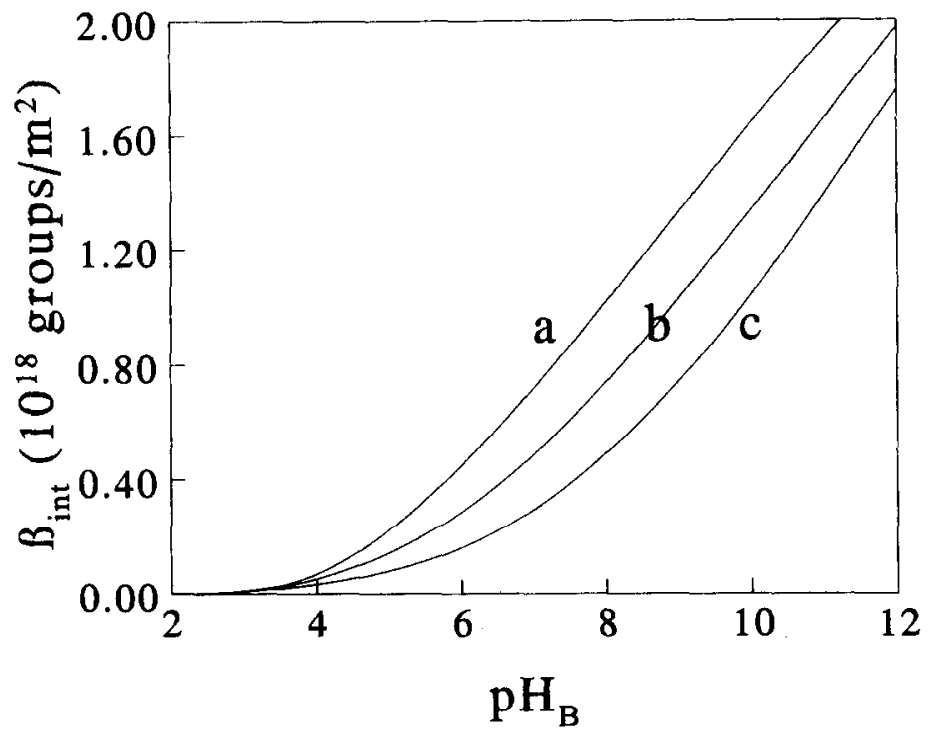

Fig. 12. The intrinsic buffer capacity of $\mathrm{a} \mathrm{SiO}_{2}$ ISFET using the site-dissociation model and the Gouy-Chapman-Stern model with $\mathrm{C}_{\mathrm{i}, \mathrm{st}}=0.80 \mathrm{~F} / \mathrm{m}^{2}$ (Eq. (3.24)): (a) $0.1 \mathrm{M}$, (b) $0.01 \mathrm{M}$, (c) $1 \mathrm{mM}$.

curves of the sensitivity parameter versus the bulk $\mathrm{pH}$ depicted in Fig. 11. Figure 12 shows that this low sensitivity is due to a very low intrinsic buffer capacity around the point of zero charge. When the intrinsic buffer capacity rises the sensitivity increases to $54 \mathrm{mV} / \mathrm{pH}$ at $\mathrm{pH}$ 7. The differential capacitance is of minor influence as can be seen from the higher sensitivity in the neutral and acidic region (Fig. 11), although the differential capacitance is higher in these regions (Fig. 13). Figure 13 shows furthermore that the minimum differential capacitance is not at the point of zero charge, but is shifted towards the neutral region due to influence of the $\mathrm{H}+$ concentration on the ionic strength.

The theoretical response, the sensitivity, the differential capacitance and the intrinsic buffer capacity calculated with a Stern layer capacitance of $0.2 \mathrm{~F} / \mathrm{m}^{2}$ are similar to that calculated with a capacitance of $0.8 \mathrm{~F} / \mathrm{m}^{2}$. The theoretical response and sensitivity calculated with a Stern layer capacitance of $0.8 \mathrm{~F} / \mathrm{m}^{2}$ is over the entire region a little lower than the response and the sensitivity calculated with a Stern layer capacitance of $0.2 \mathrm{~F} / \mathrm{m}^{2}$ (not shown). Furthermore, the variation in the sensitivity due to a change in the ionic strength is higher 


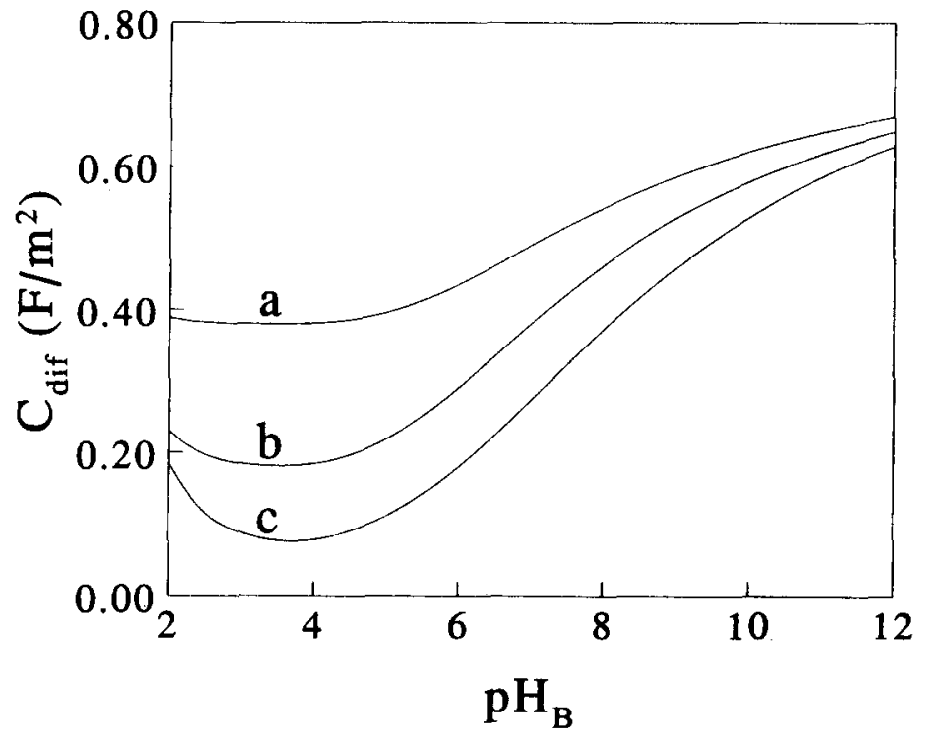

Fig. 13. The differential capacitance of a $\mathrm{SiO}_{2}$ ISFET using the site-dissociation model and the Gouy-Chapman-Stern model with $\mathrm{C}_{\mathrm{i}, \mathrm{st}}=0.80 \mathrm{~F} / \mathrm{m}^{2}$ (Eq. (3.44)): (a) $0.1 \mathrm{M}$, (b) $0.01 \mathrm{M}$, (c) $1 \mathrm{mM}$.

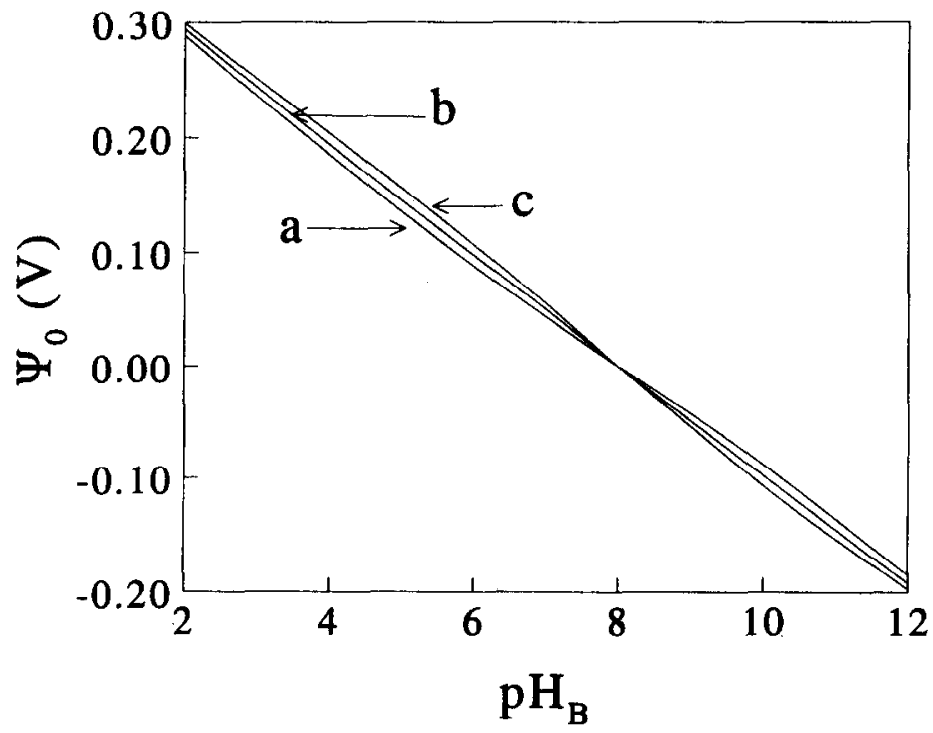

Fig. 14. The theoretical total response of a $\mathrm{Al}_{2} \mathrm{O}_{3}$ ISFET using the site-dissociation model and the Gouy-Chapman-Stern model with $\mathrm{C}_{\mathrm{i}, \mathrm{st}}=0.80 \mathrm{~F} / \mathrm{m}^{2}$ (Eq. (3.47)): (a) $0.1 \mathrm{M}$, (b) $0.01 \mathrm{M}$, (c) $1 \mathrm{mM}$. 
for a higher Stern capacitance. The variations in the sensitivity are caused by a relatively high variation in the differential capacitance.

\section{Aluminum oxide}

Figure 14 shows the theoretical response of $\mathrm{Al}_{2} \mathrm{O}_{3}$ ISFETs using a Stern capacitance of $0.8 \mathrm{~F} / \mathrm{m}^{2}$. In both cases the maximum variation in the sensitivity is around the point of zero charge (Fig. 15). This variation is due to the influence of the electrolyte concentration on the differential capacitance (Fig. 16). Further from the point of zero charge the rise of the differential capacity is compensated by the rise of the intrinsic buffer capacity (Fig. 17). In contrast to silicon dioxide the minimum in the differential capacitance is at the point of zero charge.

The theoretical sensitivity is slightly smaller when a Stern layer of $0.8 \mathrm{~F} / \mathrm{m}^{2}$ is used compared to a Stern layer of $0.2 \mathrm{~F} / \mathrm{m}^{2}$. This sensitivity is lower over the entire $\mathrm{pH}$ range, although the intrinsic buffer capacity rises relatively strongly. Just like in the case of silicon dioxide the influence of the ionic strength on the electrostatic potential is higher for higher Stern layer capacitances.

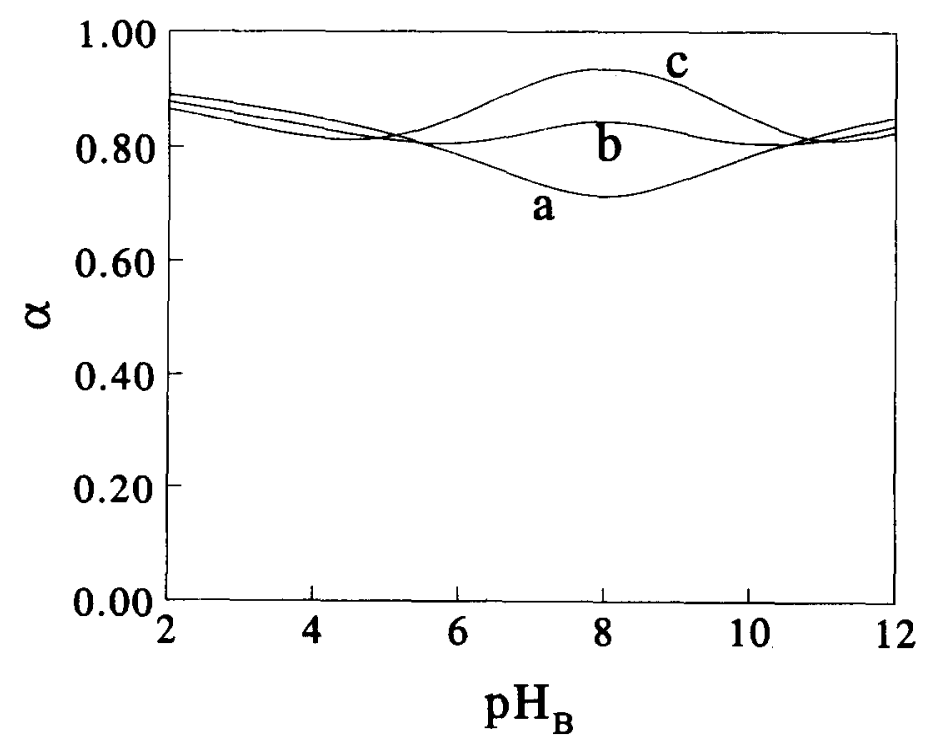

Fig. 15. The sensitivity parameter of a $\mathrm{Al}_{2} \mathrm{O}_{3}$ ISFET using the site-dissociation model and the Gouy-Chapman-Stern model with $\mathrm{C}_{\mathrm{i}, \mathrm{st}}=0.80 \mathrm{~F} / \mathrm{m}^{2}$ (Eq. (3.10)): (a) $0.1 \mathrm{M}$, (b) $0.01 \mathrm{M}$, (c) $1 \mathrm{mM}$. 


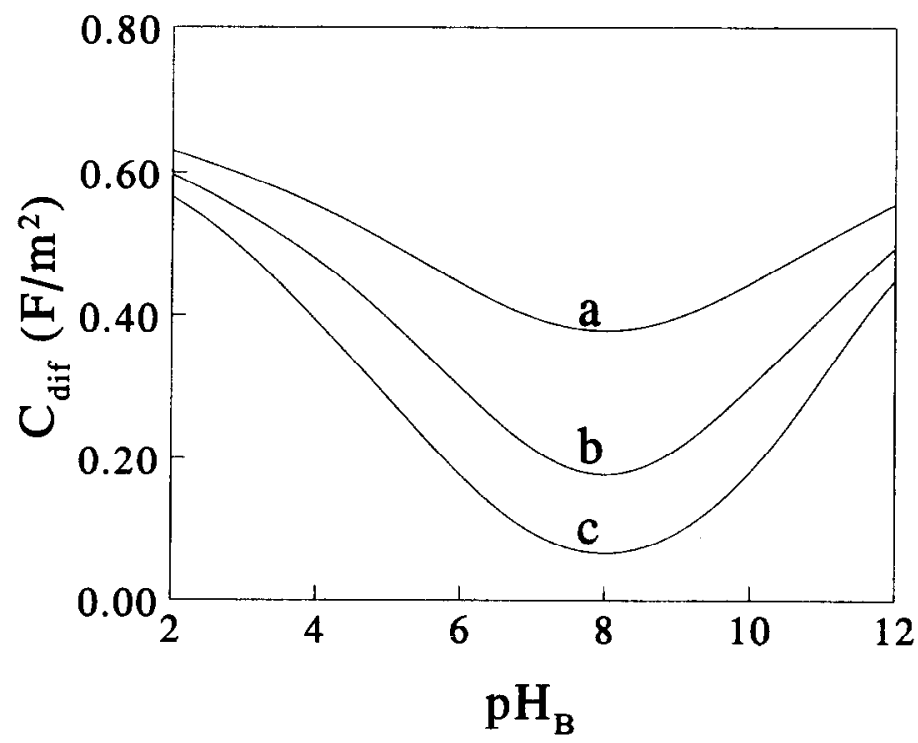

Fig. 16. The differential capacitance of $\mathrm{Al}_{2} \mathrm{O}_{3}$ ISFET using the site-dissociation model and the Gouy-Chapman-Stern model with $\mathrm{C}_{\mathrm{i}, \mathrm{st}}=0.80 \mathrm{~F} / \mathrm{m}^{2}$ (Eq. (3.44)): (a) $0.1 \mathrm{M}$, (b) $0.01 \mathrm{M}$, (c) $1 \mathrm{mM}$.

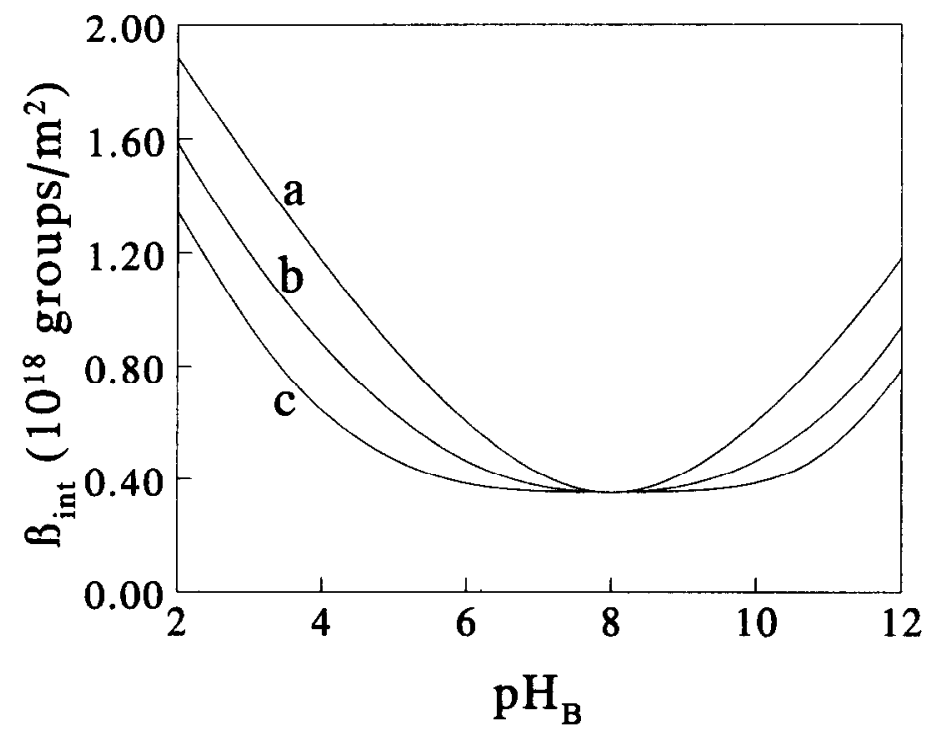

Fig. 17. The intrinsic buffer capacity of a $\mathrm{Al}_{2} \mathrm{O}_{3}$ ISFET using the site-dissociation model and the Gouy-Chapman-Stern model with $\mathrm{C}_{\mathrm{i}, \mathrm{st}}=0.80 \mathrm{~F} / \mathrm{m}^{2}$ (Eq. (3.24)): (a) $0.1 \mathrm{M}$, (b) $0.01 \mathrm{M}$, (c) $1 \mathrm{mM}$. 


\subsection{MUSIC and Gouy-Chapman-Stern model}

The MUSIC model is generally used in combination with the GouyChapman-Stern model. In 1991 Hiemstra and Van Riemsdijk argued that the capacitance of the Stern layer is between 0.8 and $1.6 \mathrm{~F} / \mathrm{m}^{2}$ [20]. Nowadays, they assume that the real value lies close to the lower limit [13]. A Stern layer capacitance of $0.8 \mathrm{~F} / \mathrm{m}^{2}$ will therefore be used in the next section.

\section{Silicon dioxide}

The site-dissociation model for $\mathrm{SiO}_{2}$ can be regarded as a special case of the MUSIC model. The slight difference between the calculated value of 7.5 for $\mathrm{pK}_{\mathrm{a}}$, in the MUSIC model [12] and the value of 6 used in the site-dissociation model causes a shift of the curves given in Figs. 10, 11, 12 and 13 towards the basic region.

\section{Aluminum oxide}

The relation between the parameters $\mathrm{a}_{\mathrm{H}_{S}^{+}}$and $\psi_{0}$ can be derived by combining Eqs. (5) and (29) to obtain:

$$
\mathrm{a}_{\mathrm{H}_{\mathrm{S}}^{+}}=\frac{\mathrm{K}_{\mathrm{e}}\left(\mathrm{C}_{\mathrm{i}} \psi_{0}+0.5 \mathrm{qN} \mathrm{N}_{\mathrm{s}}\right)}{0.5 \mathrm{qN}_{\mathrm{s}}-\mathrm{C}_{\mathrm{i}} \psi_{0}}
$$

The intrinsic dissociation constant $\mathrm{K}_{\mathrm{e}}\left(10^{-8.5}\right)$ given in Eq. (26), is calculated from crystallographic measurements [13]. Figure 18 shows the theoretical electrostatic potential of aluminum oxide as function of $\mathrm{pH}_{\mathrm{B}}$. The sensitivity is almost independent of the ionic strength (Fig. 19). Figure 20 shows that the variations are small due to the very high intrinsic buffer capacity in the MUSIC model. The high buffer capacity reduces the influence of variations in the differential capacitance (Fig. 21). There is a maximum sensitivity at the point of zero charge (Fig. 19). The sensitivity reduces going from the point of zero charge due to a rise in the differential capacitance in combination with a decrease in the intrinsic buffer capacity.

Note that the variations in the electrostatic potential are much smaller than in case the site-dissociation model is used to describe the surface charging mechanism. 


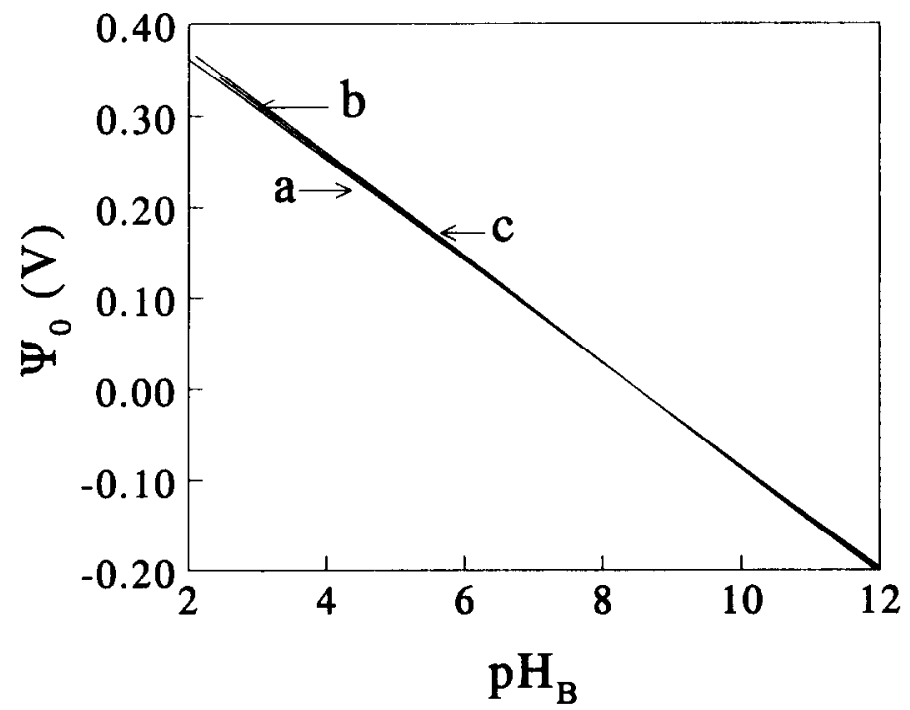

Fig. 18. The theoretical total response of a $\mathrm{Al}_{2} \mathrm{O}_{3}$ ISFET using the MUSIC model and the Gouy-Chapman-Stern model with $\mathrm{C}_{\mathrm{i}, \mathrm{st}}=0.80 \mathrm{~F} / \mathrm{m}^{2}$ (Eq. (3.48)): (a) $0.1 \mathrm{M}$, (b) 0.01 $\mathrm{M}$, (c) $1 \mathrm{mM}$.

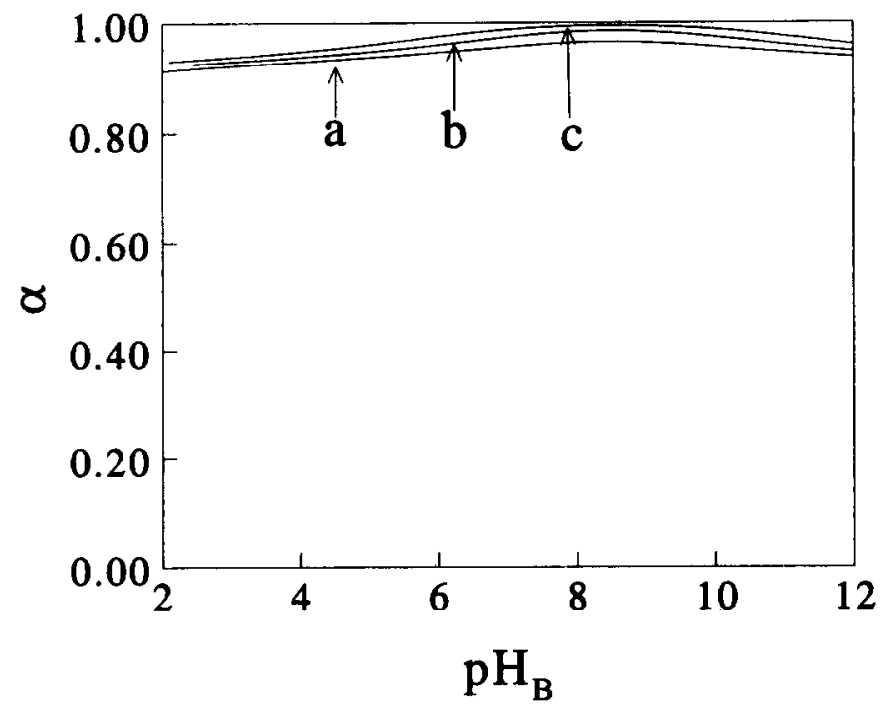

Fig. 19. The sensitivity parameter of a $\mathrm{Al}_{2} \mathrm{O}_{3}$ ISFET using the MUSIC model and the Gouy-Chapman-Stern model with $\mathrm{C}_{\mathrm{i}, \mathrm{st}}=0.80 \mathrm{~F} / \mathrm{m}^{2}$ (Eq. (3.10)): (a) $0.1 \mathrm{M}$, (b) $0.01 \mathrm{M}$, (c) $1 \mathrm{mM}$. 


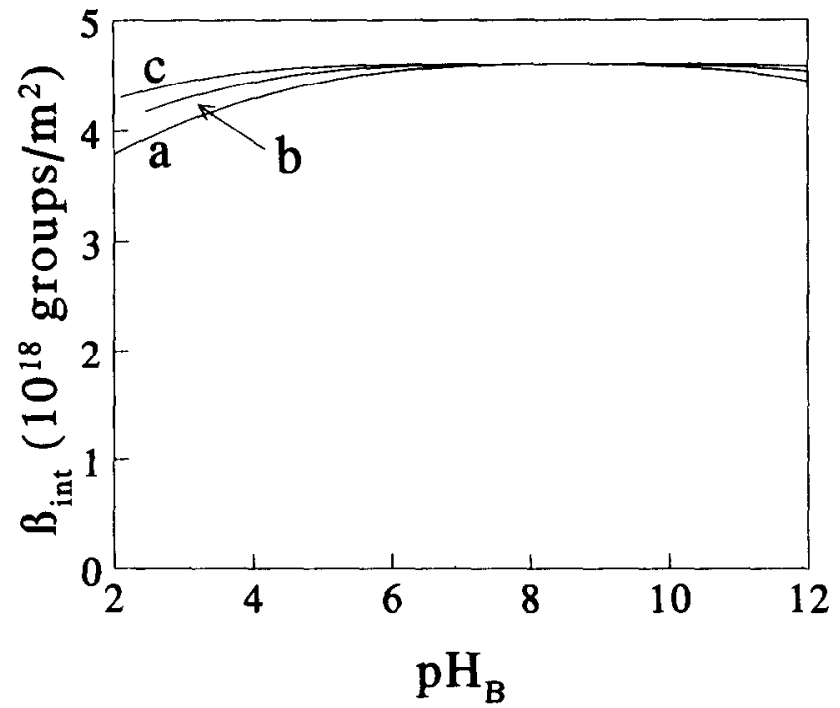

Fig. 20. The intrinsic buffer capacity of a $\mathrm{Al}_{2} \mathrm{O}_{3}$ ISFET using the MUSIC model and the Gouy-Chapman-Stern model with $\mathrm{C}_{\mathrm{i}, \mathrm{st}}=0.80 \mathrm{~F} / \mathrm{m}^{2}$ (Eq. (3.39)): (a) $0.1 \mathrm{M}$, (b) $0.01 \mathrm{M}$, (c) $1 \mathrm{mM}$.

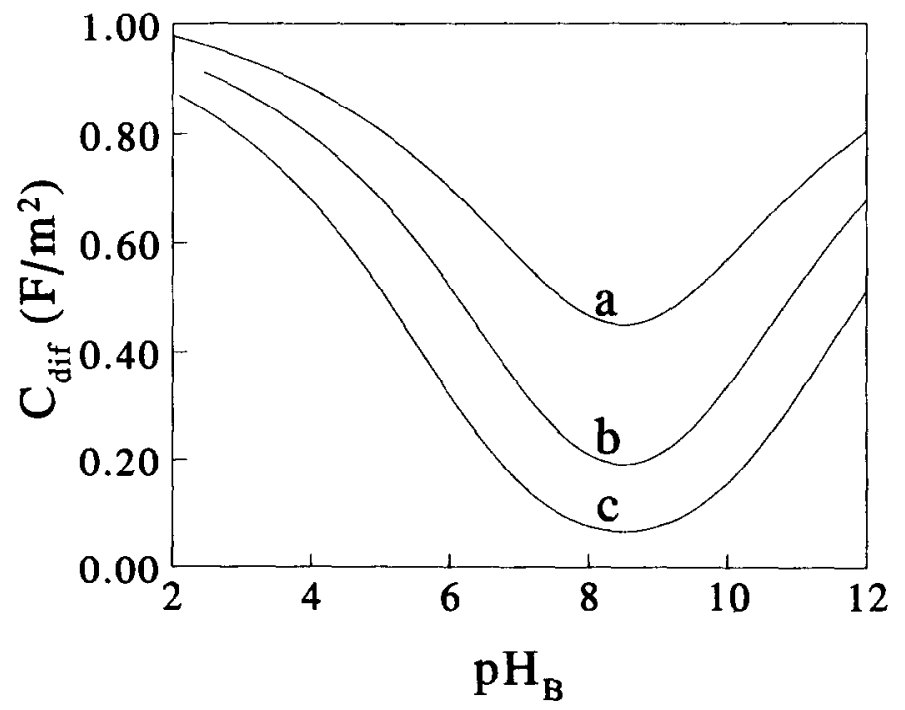

Fig. 21. The differential capacitance of $\mathrm{a}_{2} \mathrm{O}_{3}$ ISFET using the MUSIC model and the Gouy-Chapman-Stern model with $\mathrm{C}_{\mathrm{i}, \mathrm{st}}=0.80 \mathrm{~F} / \mathrm{m}^{2}$ (Eq. (3.44)): (a) $0.1 \mathrm{M}$, (b) $0.01 \mathrm{M}$, (c) $1 \mathrm{mM}$ 


\section{Experimental verification and discussion}

Figure 22 shows the experimental response of several ISFETs with different gate materials to changes in the $\mathrm{pH}$ in a $0.1 \mathrm{M}$ electrolyte solution. The sensitivity of ISFETs with $\mathrm{SiO}_{2}$ as the gate material is remarkably lower around the point of zero charge, whereas it is as high as $-45 \mathrm{mV} / \mathrm{pH}$ in the neutral area. Thus, the sensitivity parameter lies between almost 0 and 0.75 . The sensitivity of ISFETs with an $\mathrm{Al}_{2} \mathrm{O}_{3}$ gate is nearly constant at $-54 \mathrm{mV} / \mathrm{pH}$. The sensitivity parameter, $\alpha$, is calculated to be around 0.9 . The sensitivity of $\mathrm{Ta}_{2} \mathrm{O}_{5}$ ISFETs is even higher and is about $-58 \mathrm{mV} / \mathrm{pH}$ and thus $\alpha$ is above 0.95 .

In Fig. 23, the experimental response and the theoretical response, using several combinations of models, for $\mathrm{SiO}_{2}$ ISFETs are compared. The theoretical response calculated with the site-dissociation model and the Gouy-Chapman model gives a reasonable description of the ISFET response in the acidic and neutral region. However, in the basic region the theoretical sensitivity approaches zero, whereas the experimental sensitivity reaches its maximum. For a better fit in the basic region a larger number of sites is required.

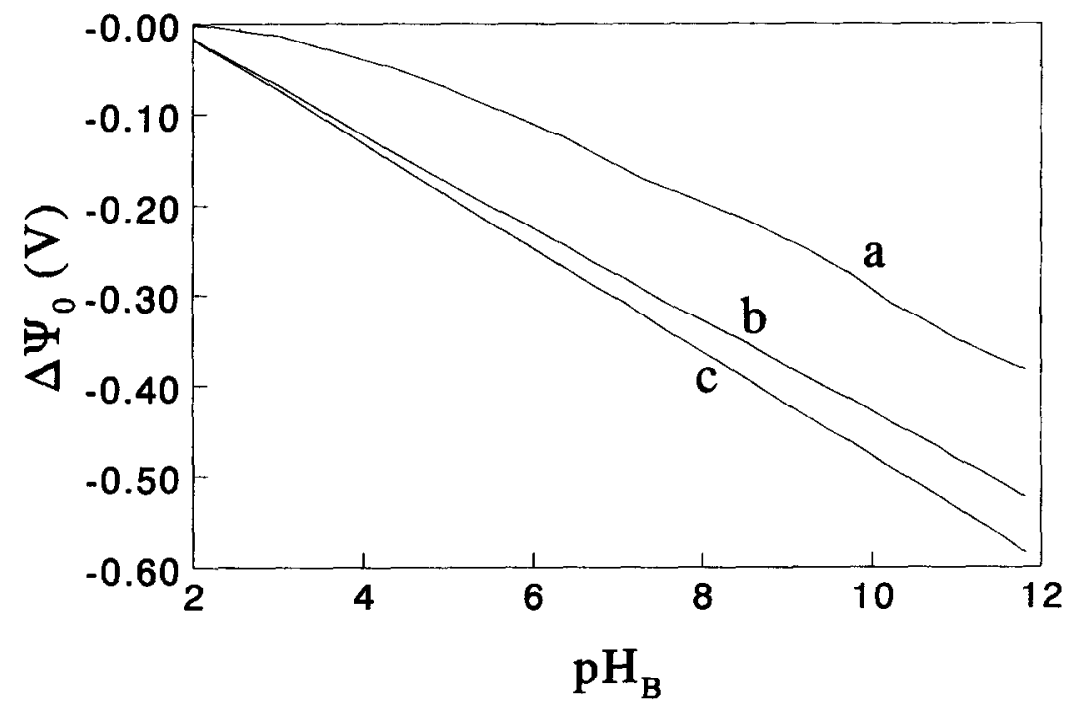

Fig. 22. The experimental total response of (a) $\mathrm{SiO}_{2}$, (b) $\mathrm{Al}_{2} \mathrm{O}_{3}$ and (c) $\mathrm{Ta}_{2} \mathrm{O}_{5}$ ISFETs. 


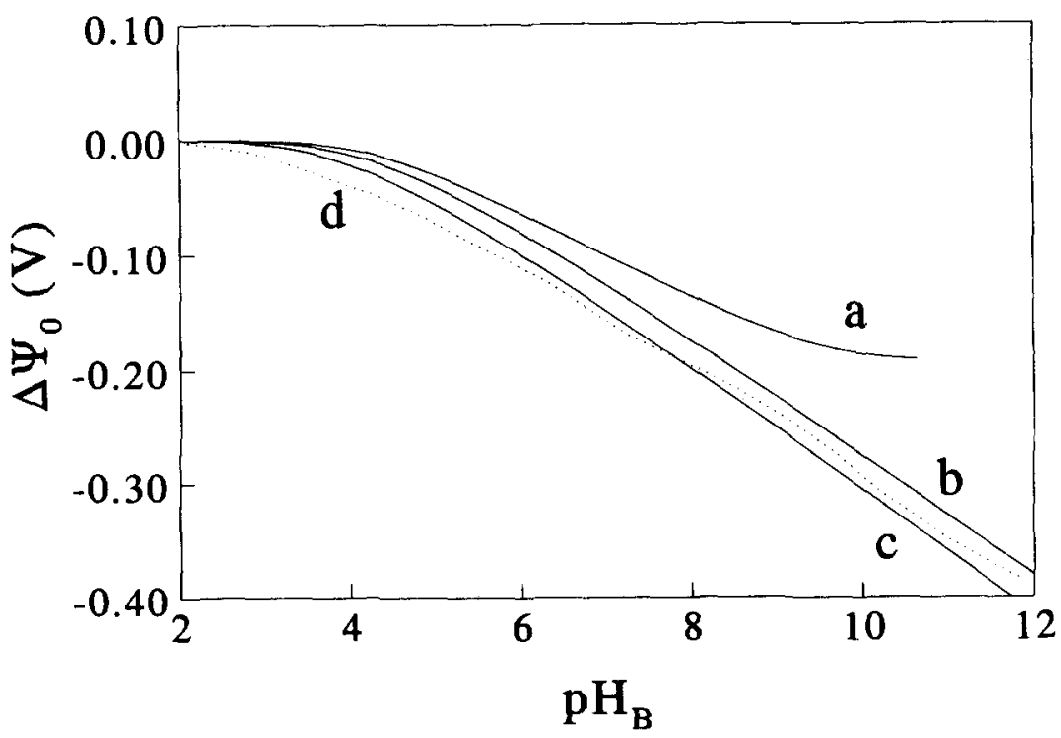

Fig. 23. The theoretical and the experimental total responses of a $\mathrm{SiO}_{2}$ ISFET: (a) Site-dissociation model with Gouy-Chapman model, (b) Site-dissociation model with Gouy-Chapman-Stern model $\left(\mathrm{C}_{\mathrm{i}, \mathrm{st}}=0.80 \mathrm{~F} / \mathrm{m}^{2}\right)$, (c) Site-dissociation model with GouyChapman-Stern model $\left(\mathrm{C}_{\mathrm{i}, \mathrm{st}}=0.20 \mathrm{~F} / \mathrm{m}^{2}\right)$, (d) experimental.

The site-dissociation model and the MUSIC model describe the charging mechanism of $\mathrm{SiO}_{2}$ by the same surface reactions. The sitedissociation model can be regarded as a special case of the MUSIC model. The experimental sensitivity in the acidic region is slightly higher than the theoretical sensitivity. A better fit is obtained when higher values for the Stern layer are used. However, perhaps $\mathrm{SiO}_{2}$ can not be described by this model at all, because it is known that the surface of $\mathrm{SiO}_{2}$ is hydrolysed up to a depth of at least $10 \AA$ [21].

Figure 24 shows the experimental and theoretical response of $\mathrm{Al}_{2} \mathrm{O}_{3}$ ISFETs. The sensitivity is one of the main parameters to distinguish between the three models. The theoretical response calculated with the site-dissociation model and the Gouy-Chapman model, for the double layer, is over the entire $\mathrm{pH}$ range lower than the experimental response. A higher number of the surface sites and a smaller $\Delta \mathrm{pK}$ will increase the intrinsic buffer capacity and thus the sensitivity. However, due to the high value of the differential capacitance, the surface is completely titrated in the acidic region, causing a decrease in the sensitivity. There is no reasonable fit of the parameters possible to prevent the reduced sensitivity in the acidic region. 


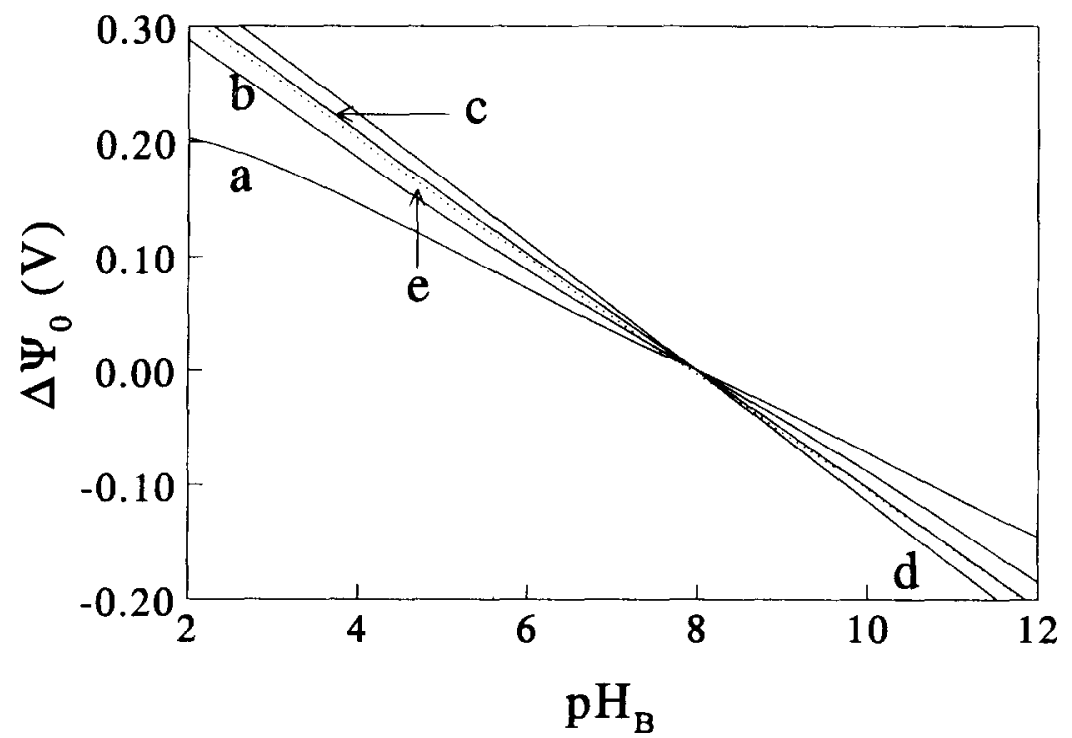

Fig. 24. The theoretical and the experimental total responses of a $\mathrm{Al}_{2} \mathrm{O}_{3}$ ISFET: (a) Site-dissociation model with Gouy-Chapman model, (b) Site-dissociation model with Gouy-Chapman-Stern model $\left(\mathrm{C}_{\mathrm{i}, \mathrm{st}}=0.80 \mathrm{~F} / \mathrm{m}^{2}\right)$, (c) Site-dissociation model with GouyChapman-Stern model $\left(\mathrm{C}_{\mathrm{i}, \mathrm{st}}=0.20 \mathrm{~F} / \mathrm{m}^{2}\right)$, (d) MUSIC model with Gouy-Chapman-Stern model $\left(\mathrm{C}_{\mathrm{i}, \mathrm{st}}=0.80 \mathrm{~F} / \mathrm{m}^{2}\right),(\mathrm{e})$ experimental.

The response calculated with the site-dissociation model and the Gouy-Chapman-Stern model fits very well with the measured response especially in the case of a Stern layer capacitance of $0.2 \mathrm{~F} / \mathrm{m}^{2}$. The slight decrease in sensitivity at the point of zero charge is not visible in the ISFET response curve (Fig. 24).

The response calculated with the MUSIC model gives a better fit for the measured ISFET response. The calculated sensitivity is slightly higher than the measured sensitivity. A lower number of surface sites or a higher value for the Stern layer capacitance will reduce the sensitivity. The slight decrease in sensitivity far from the point of zero charge, predicted by the MUSIC model, is not visible in the measured ISFET response shown in Fig. 24.

It is not possible to give a good distinction between the MUSIC model and the site-dissociation model based on the experimental results. However, the MUSIC model gives a slight increase in sensitivity around the point of zero charge whereas the site-dissociation model predicts a slight decrease at the point of zero charge. This difference is most obvious at high electrolyte concentrations and might in the future, with 
a better measurement set-up or with other oxides with a more pronounced variation, be sufficient to distinguish between both models.

\section{Conclusions}

The sensitivity of the electrostatic potential to changes in $\mathrm{pH}_{\mathrm{B}}$, as measured with an ISFET, can be very well described in terms of the intrinsic buffer capacity of the surface and the differential capacitance. This expression can be used for all theories that describe the charge of an oxide electrolyte solution interface as a result of specific interactions at specific sites. A theoretical value for the sensitivity can be calculated using several combinations of models.

The experimental sensitivities of $\mathrm{SiO}_{2}$ and $\mathrm{Al}_{2} \mathrm{O}_{3}$ ISFETs are compared with the theoretical sensitivities using the site-binding model and Gouy-Chapman model to calculate the intrinsic buffer capacity and the differential capacitance. Although this combination gave good results for the description of zeta potentials and titration data, it is not able to give a good description for the sensitivity of the electrostatic potential to changes in $\mathrm{pH}_{\mathrm{B}}$.

A better agreement with the experimental results was obtained by the combination of the Gouy-Chapman-Stern model with the site-dissociation model or with the MUSIC model. In both cases, it is possible to give several combinations of parameters to fit the experimental response. However, it was not possible yet to distinguish between both models.

\section{Acknowledgements}

This research was financially supported by the Technology Foundation of the Netherlands (STW) and the Dutch Foundation for Fundamental Research on Matter (FOM).

\section{References}

[1] P. Bergveld and A. Sibbald, Analytical and Biomedical Applications of ISFETs. Elsevier, Amsterdam, 1988.

[2] P. Bergveld, Development of an ion-sensitive solid-state device for neurophysiological measurements. IEEE Trans. Biomed. Eng., BME-17 (1970) 70.

[3] D.E. Yates, S. Levine and T.W. Healy, Site-binding model of the electrical double layer at the oxide/water interface. J. Chem. Soc. Faraday Trans. I, 70 (1974) 
1807-1818.

[4] L. Bousse, N.F. De Rooij and P. Bergveld, IEEE Trans. Electron. Dev., ED-30 (1983) 1263-1270.

[5] W.M. Siu and R.S.C. Cobbold, Basic properties of the electrolyte--SiO ${ }_{2}-\mathrm{Si}$ system: Physical and theoretical aspects. IEFF Trans. Flectron Devices, ED-26 (1979) 1805-1815.

[6] J. Lyklema, Croatica Chem. Acta, 43 (1971) 249.

[7] J.W. Perram, R.J. Hunter and H.J.L. Wright, The oxide-solution interface, Aust. J. Chem., 27 (1974) 461-475.

[8] T. Hiemstra, W.H. van Riemsdijk and G.H. Bolt, Multisite proton adsorption modelling at the solid/solution interface of (hydr)oxides: A new approach. J. Colloid Interface Sci., 133 (1989) 91-104.

[9] G.H. Bolt and W.H. van Riemsdijk, in: G.H. Bolt (Ed.), Soil Chemistry. B. Physio-chemical Models. Elsevier, Amsterdam, 1982.

[10] L. Bousse, thesis, Technische Hogeschool Twente, 1982.

[11] L. Bousse, S. Mostarshed, B. Van Der Schoot, N.F. De Rooij, P. Gimmel and W. Gopel, Zeta potential measurements of $\mathrm{Ta}_{2} \mathrm{O}_{5}$ and $\mathrm{SiO}_{2}$ films. J. Colloid Interface Sci., 147 (1991) 22-32.

[12] T. Hiemstra, J.C.M. de Wit and W.H. van Riemsdijk, Multisite proton adsorption modeling at the solid/solution interface of (hydr)oxides: A new approach. J. Colloid Interface Sci., 133 (1989) 105-117.

[13] Private communications with T. Hiemstra.

[14] J. Westall and $\mathrm{H}$. Hohl, $\Lambda$ comparison of electrostatic models for the oxide/solution interface. Adv. Coll. Interf. Sci., 12 (1980) 265-294.

[15] R.J. Hunter, Zeta Potential in Colloid Science. Academic Press, London, 1981.

[16] J.C. Van Kerkhof, J.C.T. Eijkel and P. Bergveld, ISFET responses on a stepwise change in electrolyte concentration at constant $\mathrm{pH}$. Sensors Actuators B, 18 (1994) $56-59$

[17] D.A. Dzombak and F.M.M. Morel, Surface Complexation Modelling. Hydrous Ferric Oxide. John Wiley \& Sons, New York, 1990.

[18] A.J. Bard and Faulkner, Electrochemical Methods Fundamentals and Applications. John Wiley \& Sons, New York, 1980.

[19] O. Stem, Z. Elektrochem., 30 (1924) 508.

[20] T. Hiemstra and W.H. Van Riemsdijk, Physical chemical interpretation of primary charging behaviour of metal (hydr)oxides. Colloids Surfaces, 59 (1991) 7-25.

[21] Doremus, J. Phys. Chem., 75 (1971) 3147. 